\title{
Deciphering the Complexity of 3D Chromatin Organization Driving Lymphopoiesis and Lymphoid Malignancies
}

\author{
Laurianne Scourzic $^{\dagger}$, Eralda Salataj ${ }^{\dagger}$ and Effie Apostolou * \\ Sanford I. Weill Department of Medicine, Sandra and Edward Meyer Cancer Center, Weill Cornell Medicine, New York, \\ NY, United States
}

\section{OPEN ACCESS}

Edited by:

Ageliki Tsagaratou,

University of North Carolina at Chapel Hill, United States

Reviewed by: Ralph Stadhouders, Erasmus Medical Center, Netherlands Mikhail Spivakov,

MRC London Institute of Medical Sciences, United Kingdom Rudolf Grosschedl,

Max Planck Institute for Immunobiology and Epigenetics,

Germany

*Correspondence: Effie Apostolou efa2001@med.cornell.edu

${ }^{\dagger}$ These authors have contributed equally to this work

Specialty section: This article was submitted to B Cell Biology, a section of the journal

Frontiers in Immunology

Received: 19 February 2021 Accepted: 26 April 2021

Published: 14 May 2021

Citation:

Scourzic L, Salataj E and Apostolou E (2021) Deciphering the Complexity of 3D Chromatin Organization Driving Lymphopoiesis and Lymphoid Malignancies.

Front. Immunol. 12:669881. doi: 10.3389/fimmu.2021.669881
Proper lymphopoiesis and immune responses depend on the spatiotemporal control of multiple processes, including gene expression, DNA recombination and cell fate decisions. High-order 3D chromatin organization is increasingly appreciated as an important regulator of these processes and dysregulation of genomic architecture has been linked to various immune disorders, including lymphoid malignancies. In this review, we present the general principles of the $3 \mathrm{D}$ chromatin topology and its dynamic reorganization during various steps of $\mathrm{B}$ and $\mathrm{T}$ lymphocyte development and activation. We also discuss functional interconnections between architectural, epigenetic and transcriptional changes and introduce major key players of genomic organization in $B / T$ lymphocytes. Finally, we present how alterations in architectural factors and/or 3D genome organization are linked to dysregulation of the lymphopoietic transcriptional program and ultimately to hematological malignancies.

Keywords: 3D chromatin organization, lymphopoiesis, activation, lymphoid malignancies, B cells, T cells

\section{INTRODUCTION}

Over the past decades, plethora of studies have documented the transcriptional network that controls immune cell regulation and plasticity during lymphocyte development and differentiation (1-3). The lineage commitment of early hematopoietic progenitors to a specific B or T lymphocyte is a multi-step process controlled by critical cytokines and transcription factors (TF) (Figure 1), which ultimately promote activation of $\mathrm{B} / \mathrm{T}$ cell fate programs, while posing strict checkpoints to prevent differentiation to competing lineages (4-6). Briefly, hematopoietic stem cells (HSC) within the bone marrow differentiate and give rise to a common myeloid or lymphoid progenitor (CMP and CLP, respectively). B cell development continues within the bone marrow and leads to progressive differentiation to pro- $B$, pre- $B$, and naive $B$ cells. Upon antigen encounter in the periphery, naive B cells become germinal center (GC) B cells and can either differentiate into longlived antibody secreting plasma cells or memory B cells (7). On the other hand, T cell development occurs in the thymus, where cells transition from several double negative (DN) stages into the double positive (DP) state when both functional T cell receptors (TCR) CD4 and CD8 are coexpressed. Eventually, only one type of receptor dominates giving rise to either $\mathrm{CD} 4^{+}$or $\mathrm{CD} 8^{+} \mathrm{T}$ cells. 


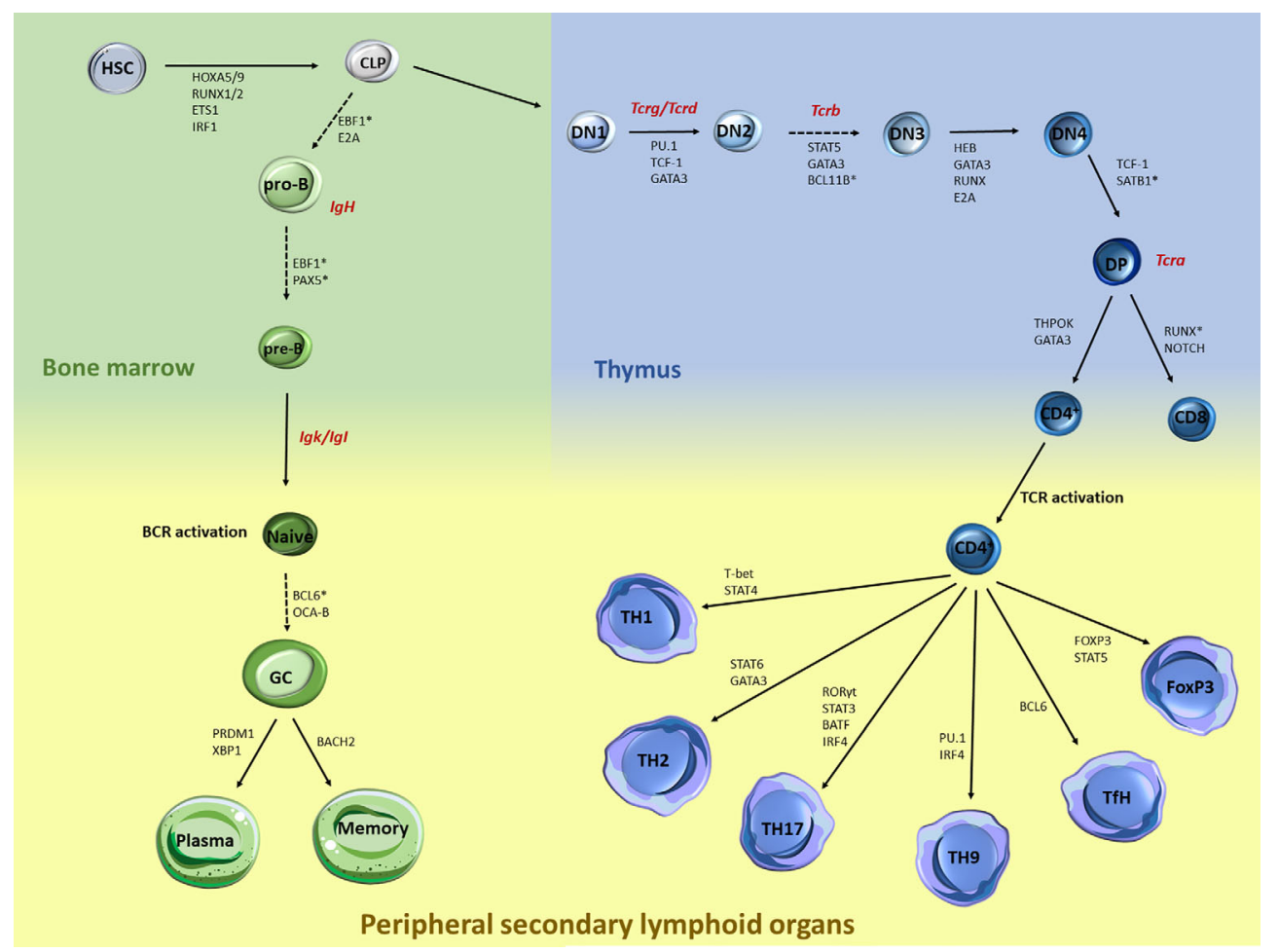

FIGURE 1 | Major stages during B and T lymphocyte specification and differentiation and key transcription factors that control each transition. B and T cell development and differentiation is a stepwise process that involves multiple specification steps, cell fate bifurcations and cell migration. Multiple TFs, including but not limited to those acting at the chromatin level, have been extensively documented in HSC. Within the bone marrow, the transition of CLP towards pro-B cells is mediated through EBF1 and E2A, while the further maturation of the pre-B cells is under the control of EBF1 and PAX5. Upon BCR activation, BCL6 and OCA-B are controlling the differentiation of naive to GC cells, while the latest developmental stages are mediated through BACH2 for memory B cells and PRDM1 and XBP1 for plasma cells. Similarly, T cell development is also regulated by a strong network of TF, cytokines and genome organizers that control chromatin dynamics and T cell lineage specification. Upon thymocyte migration, the early steps of the thymocyte development are mediated through the genome organizers SATB1 and BCL11B while TF such as PU.1, TCF1 and GATA3 mediate the generation of the DN1 cells. The transition from the DN2 to DN3 is mediated by the STAT5, GATA3 and BCL11B, while RUNX, GATA3, HEB and E2A mediate the DN3 and DN4 transition. TCF-1 is also the major TF driving the DN4 to DP transition. The last steps of the intrathymic development are mediated through the expression of ThPOK and GATA3 for the CD4 ${ }^{+}$cells and NOTCH and RUNX for the CD8 ${ }^{+}$cells. Upon TCR activation, expression of the master regulator T-bet via STAT4 signaling leads to TH1 differentiation, while STAT6 and GATA3 regulate the TH2 differentiation. Activation of STAT3 and ROR $\gamma$ leads to TH17 cells, while IRF4 and PU-1 induce the differentiation towards TH9 cells. Activation of Bcl-6 induces the differentiation of naive $\mathrm{CD}^{+} \mathrm{T}$ cells into TfH. Differentiation of the Tregs is controlled by the transcription factor Foxp3 and STAT5. Generation of Tcr/lg receptor diversity through VDJ recombination takes place at various stages during B/T lymphocyte development as depicted (red).

The thymic exodus of the naive $\mathrm{CD} 4^{+}$cells to the secondary lymphoid organs leads to further differentiation into several $\mathrm{T}$ helper $(\mathrm{TH})$ cell subpopulations $(3,8)$.

Transcriptional regulation during lymphopoiesis relies on the activity of cell state specific TFs which can function as pioneer factors and enable chromatin landscape remodeling through the recruitment of coactivators or corepressors $(1,9,10)$. Along with changes in DNA methylation and histone post-transcriptional modifications (PTM) during B/T cell differentiation, recent studies started appreciating the dynamic $3 \mathrm{D}$ chromatin reorganization and its association with transcriptional regulation and cell fate control in the immune system $(11,12)$. 3D chromatin folding and nuclear architecture play important roles in various cellular functions including gene expression, DNA replication, recombination and immune response modulation $(11,13-18)$. The development of chromosome conformation capture (3C) and high-resolution imaging and their derivatives (19-22) enabled the investigation of different hierarchical layers of chromatin organization based on the genome-wide identification of chromatin contacts. At the highest level of chromatin folding, individual interphase chromosomes occupy distinct regions in the nucleoplasm, called Chromosome Territories (CTs) in a non-random manner, as observed by microscopy-based methods (Figure 2) (23). Each of the chromosome territories (CTs) is further organized into megabase $(\mathrm{Mb})$ level, through the segregation into $\mathrm{A}$ and $\mathrm{B}$ compartments, which are associated with euchromatin and heterochromatin, respectively $(24,25)$. Open, gene-rich and transcriptionally active chromatin regions are located within A compartments, which usually occupy the nuclear interior. B compartments are gene-poor, inactive and largely overlapping with lamina associated domains (LADs) (26), known as heterochromatic domains, located in the nuclear periphery and linked to gene repression $(27,28)$. Except from 


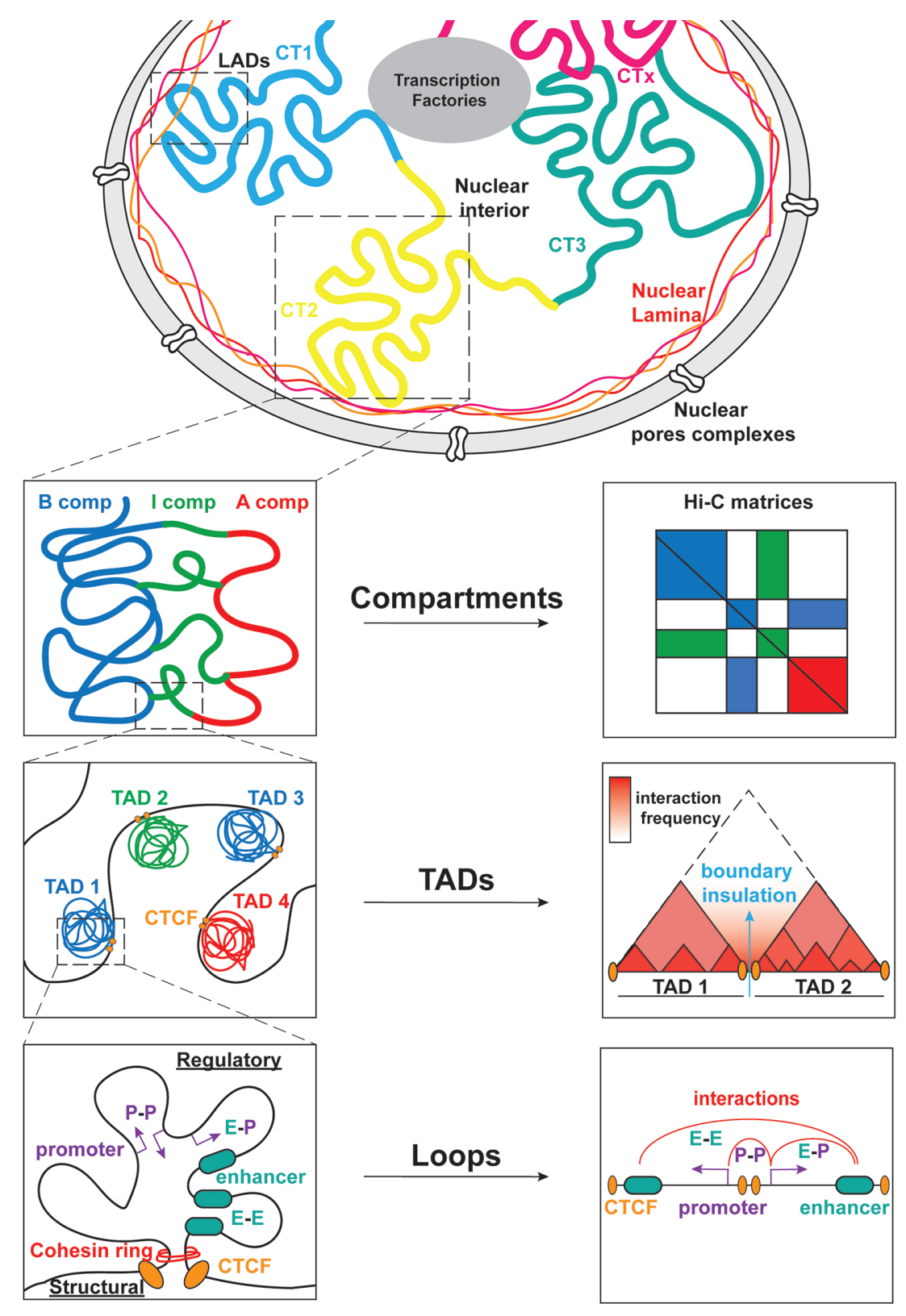

FIGURE 2 | Global genome organization in mammalian nuclei from the megabase scale to the E-P level. Mammalian nuclei are organized into chromosomes with non-random distribution in the nucleoplasm. Each chromosome is further composed of chromosome territories (CT) further subdivided into A/B/I compartments. Within these compartments, TADs allow for interactions between regulatory elements (RE) that modulate gene expression. The cis/trans interactions take place between promoters $(P-P)$, enhancers $(E-E)$ or both $(E-P)$.

the A/B compartments, recently the intermediate (I) compartments were also introduced as highly dynamic chromatin domains enriched in genes poised or repressed by the Polycomb Repressive Complex (PRC) (29). At a submegabase level of chromatin organization, we observe selfinteracting domains named topologically associating domains (TADs) $(30,31)$, which appear to be highly conserved across cell type and mammalian species. TADs (32) are demarcated by boundaries enriched in $\mathrm{CTCF} / \mathrm{Cohesin}$ that insulate them from neighboring domains and facilitate the creation of regulatory loops $(30,31)$. Finally, at the finest scale of organization, chromatin is organized into looped structures or chromatin contacts that enable physical proximity among distal regulatory elements (RE), such as enhancers and promoters. These long-range interactions have been shown to play important roles in key biological processes, including DNA recombination and regulation of gene expression and cell fate $(33-36)$. 
Over the last years, a large number of studies started mapping the hierarchical levels of 3D chromatin architecture in various stages of lymphopoiesis and immune response and reveal important insights for its role in VDJ recombination, gene expression and cell fate decisions. In this review, we will discuss key principles of chromatin reorganization during various stages of $\mathrm{B}$ and $\mathrm{T}$ lineage specification, lymphocyte differentiation as well as the coordination with gene expression and cell fate decisions. We will also speculate on specific mechanisms and factors that drive architectural rewiring in lymphocytes. Finally, we will address how the 3D chromatin dysregulation might contribute to inefficient or altered immune responses, leading eventually to leukemogenesis and lymphomagenesis.

\section{CHAPTER I: CHROMATIN REORGANIZATION DURING CLP SPECIFICATION FROM HSPC}

The degree to which chromatin accessibility and topology are remodeled during the step-wise differentiation from hematopoietic stem and progenitor cells (HSPC) to CMP and CLP (Figure 1) became recently appreciated thanks to the development of single cell (or low yield) technologies, such as scDNase-seq (37), multiple-enzyme Hi-C (3eHi-C) (38) or low input tagmentation-based Hi-C (tagHi-C) (39-41). These studies reported only limited changes at the early stages of hematopoiesis, while broad chromatin reorganization occurred at the CLP stage coinciding with a major change in cell proliferation potential (41). High resolution genome-wide contact heatmaps demonstrated that murine CLP adopt a Rabl configuration, which is defined by centromeres and telomeres localized at different poles of the nucleus (42). Transcentromeres or trans-telomeres interactions increase upon differentiation to myeloid mature populations, although it remains unclear whether this configuration persists in the lymphoid lineage. Additionally, highly expressed genes form highly interacting domains, coined as gene body associated domains (GAD), an observation that has been independently reported in multiple cell types using high resolution $\mathrm{Hi}-\mathrm{C}$ or Micro-C technologies (43-45), suggesting that high local interactivity is linked to transcriptional activity.

\section{CHAPTER II: 3D CHROMATIN REORGANIZATION DURING LYMPHOCYTE DEVELOPMENT}

\section{Large-Scale Subnuclear Changes}

As shown by $3 \mathrm{D}$ chromosome painting experiments in lymphocytes and other cell types, the radial position of CTs associates with their gene density, with gene-poor CTs localized toward the nuclear periphery, while gene-dense CTs occupy more central positions (46-50). Moreover, the position of gene loci relative to the inner or outer layer of their respective CT and/ or relative to the nuclear periphery associate with their transcriptional activity. For example, in human lymphocytes it was shown that transcriptionally active telomeres are located in the nuclear center, while heterochromatic centromeres are found in the perinuclear domains (47). Intriguingly, many early studies reported extensive repositioning of entire chromosomes or specific gene loci during thymic development, providing strong evidence for dynamic chromatin reorganization and its association with transcriptional changes (51). Specifically, CT6 (containing $C d 4$ and $C d 8 \mathrm{~T}$ cell lineage-specific loci) maintains its subnuclear position during murine thymocyte development between DN and DP cells, but relocates towards the center in $\mathrm{CD}^{+}$cells and towards the periphery in $\mathrm{CD} 8^{+}$cells. $\mathrm{Cd} 4$ and Cd8 loci loop out from the inner core of their territory (CT6) in $\mathrm{CD}^{+}$and $\mathrm{CD}^{+}$cells, respectively, whereas the non-expressing genes are embedded within interior CT domains (51). Additional examples for gene repositioning out of the CT core during T cell activation have been reported for the Ifng and the major histocompatibility locus (MHC) $(48,52-54)$. Finally, studies in $\mathrm{T}$ cells have also documented gene repositioning relative to repressive or activating subnuclear domains along with transcriptional changes. Specifically, repression of either $C d 4$ or $\mathrm{Cd} 8$ gene in mature $\mathrm{CD}^{+}$and $\mathrm{CD}^{+}$cells, respectively, was linked to their repositioning towards pericentromeric heterochromatinic $(\mathrm{PCH})$ regions $(55,56)$. Similarly, during Bcell maturation, genes have also been observed to reshuffle towards or away from heterochromatic foci enriched for the repressive protein IKAROS, in order to be inactivated (e.g. $\lambda 5$ ) or expressed (e.g. Cd2) in a stage-specific manner (57).

\section{Large-Scale Compartmentalization Changes}

The development of $3 \mathrm{C}$ technologies enabled the tracking of topological reorganization at various developmental stages and at a genome-wide level $(24,30,58,59)$. During B cell development, compartmentalization remains largely unchanged with only few $\mathrm{A}$ and $\mathrm{B}$ compartment switches between murine HSC and pro-B cells (0.7\%) (60). Focusing more specifically into the transition from pre-pro-B to pro- $\mathrm{B}$, Lin et al. detected local reorganizations, resulting in about $20 \%$ of A-to-B or B-to-A compartment switches (Figure 3). These changes were associated with increased or decreased nascent transcriptional activity, respectively, as measured by global run-on sequencing (GRO-seq) (61). Some of the largest domains that switched from a repressive to permissive chromatin state included critical B-cell regulatory genes such as Ebf1, Foxo1, $\operatorname{Ig} \kappa$ and $\operatorname{Ig} \lambda$ loci. Interestingly, most of B-to-A switched loci that showed no transcriptional upregulation were enriched instead for H3K27me3 deposition, a chromatin mark linked to poising and gene repression, indicating that the transition to a permissive compartment is not always accompanied by transcriptional changes, but also by remodeling of chromatin state.

Large-scale chromatin reorganization also occurs during $\mathrm{T}$ cell development as revealed by a recent study integrating scDnase-Seq, 3e Hi-C and RNA-Seq datasets from distinct stages of $\mathrm{T}$ cell development, starting from HSPCs and 


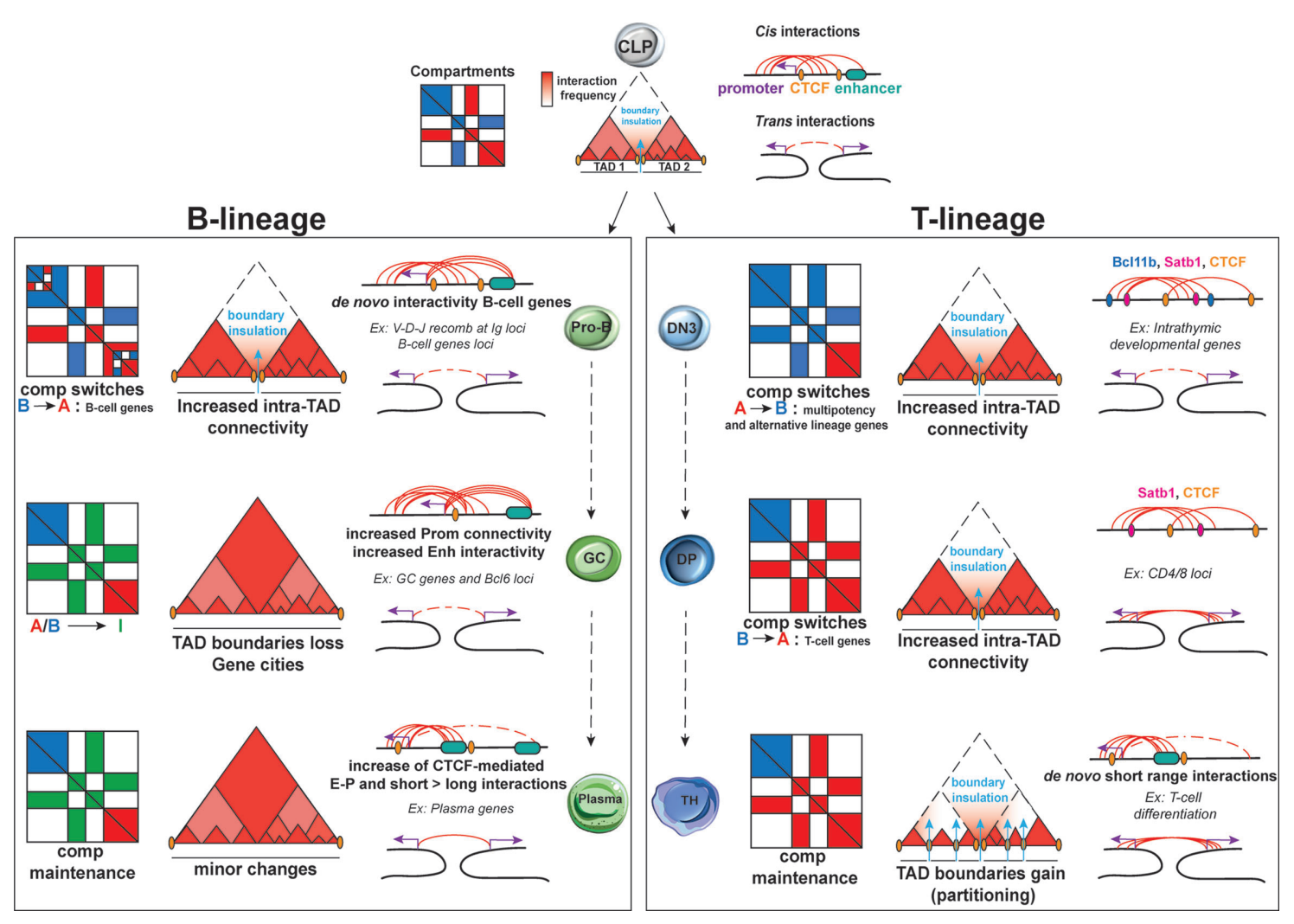

FIGURE 3 | Dynamic 3D chromatin changes during lymphocyte development and differentiation. B lineage: Upon commitment to the B-cell lineage, minor changes are documented for A/B compartments and TADs at the pro-B stage. Nonetheless, major changes in intra-TAD activity are associated with B-cell specific genes. Upon activation, GC B-cells are uniquely characterized by an increase in the weak Intermediate (I) compartments, which are maintained during plasma cells transition. TAD boundaries tend to be lost in GC B cells, leading to "gene cities" specific organization. While E-P loops tends to be increased in both GC and plasma cells, the latter subpopulation is characterized by a shift from long to short-range interactions. T lineage: During T lymphocyte development, the earliest global changes in A/B compartment, intra-TAD connectivity and loop formation take place at the T cell commitment step upon the transition of DN2 to DN3 cells but also in the DN4 to SP transition. Conversely, TCR activation does not cause changes in A/B compartments but results in TAD partitioning due to de novo and stronger TAD boundaries. A high proportion of both intra- and interchromosomal interactions are found for these 3 stages of T-cells development and differentiation for which the high E-P loop formation ensures T helper lineage specific gene expression.

including CLP, DN1, DN2, DN3, DN4 and DP cells (39). This analysis detected changes in $\mathrm{A} / \mathrm{B}$ compartmentalization with more than 1,200 genomic bins exhibiting $\mathrm{A} / \mathrm{B}$ compartment switching. Intriguingly, the majority of A-to-B switches occurred during the transition from HSPCs to DN2 cells and B-to-A during the transition from DN3 until DP stage of thymic development, suggesting a global chromatin closure during early stages of $\mathrm{T}$ cell differentiation followed by opening upon T-cell lineage commitment (Figure 3). Overall, the highest percentage of global switching of $\mathrm{A} / \mathrm{B}$ compartment during $\mathrm{T}$ cell development was observed at the DN2-to-DN3 transition, which is one of the most pivotal checkpoints for $\mathrm{T}$ lineage commitment. During this stage, genes that promote multipotency and differentiation of alternative lineages (such as Hmga, Meis1, Lmo2) undergo A-to-B compartment switching, while genes involved in T-cell maturation and selection (such as Bcl11b, Ets1, Tcf7, Cd3d, and Lef1) relocate from B-to-A compartment (39). Interestingly, integration of gene expression datasets showed that transcriptional silencing sometimes occurs prior the A-to-B compartment switching. Similarly, B-to-A compartment switches included promoters that were premarked by H3K4me3 in HSPCs, indicating that local permissive chromatin state can be independent from topological changes (both in compartments and TADs, as discussed later).

\section{TADs and Chromatin Loops}

Major TAD reorganization in B cells occurs at the $I g$ loci during $\mathrm{V}(\mathrm{D}) \mathrm{J}$ recombination $(62,63)$, which constitute the most important step of early lymphocyte development that controls the rearrangement and the expression of a diverse repertoire of $B$ and $\mathrm{T}$ receptors $(\mathrm{B} / \mathrm{TCR})(64,65)$. This process involves the de novo establishment of multiple long-range contacts along the Igh or Igא loci, which leads to locus contraction $(66,67)$ (see Chapter IV). Another example of crucial TAD reorganization has also been reported to occur around the genes that encode the recombination-activating genes (RAG) DNA cleaving enzymes necessary for the $\mathrm{V}(\mathrm{D}) \mathrm{J}$ recombination (68). The $\mathrm{B}$ or $\mathrm{T}$ cell specific expression of these genes depends on chromatin 
interaction involving lineage-specific Rag cis-regulatory elements (CRE) in $\mathrm{B}$ and $\mathrm{T}$ progenitors mediated by the E2A pioneer factor (69). One $\mathrm{T}$ cell specific (R-Ten) and two B cell specific $(R 1 B$ and $R 2 B$ ) enhancers were identified that interact with $R a g$ promoters, leading to cell type-specific sub-TAD organization. Either deletion of enhancers or mutations of the E2A binding motif were sufficient to disrupt TAD organization, long-range interactions and Rag1/2 expression. Interestingly, in macrophages the Rag1/2 locus is silenced and insulated from the neighboring active compartment through a strong TAD boundary, which is absent in pro-B/pro-T cells.

In agreement with previous studies in other cellular contexts, the number, position and average size of TADs along B cell development remains largely invariant genome-wide $(30,61,70)$. Nonetheless, significant changes in intra-TAD cis interactions were observed upon specific transitions stages. For example, Polg2, which is highly expressed and interacting with multiple enhancers in pre-pro-B, lost all chromatin contacts in pro-B. Conversely, the $C d 79 b$ and Ebf1 loci were shown to establish multiple de novo interactions in the pro-B stage $(61,70)$. At the $I g \kappa$ locus, a distal enhancer E88 forms a highly connected enhancer hub within the $\mathrm{V}$ region and its deletion results in major alterations of long-range interactions between $\mathrm{V}$ and $\mathrm{J}$ regions and reduced receptor variant diversity (71). Overall, these results suggest that while TAD genomic position maintenance is largely unaffected, intra-TAD interactions changes are most likely still crucial for cell type-specific gene expression, sustaining B cell identity and functionality.

Changes in intra-TAD organization have also been reported during T cell development (39), with many loci important for T cell lineage commitment gaining or losing interactions. A significant increase in intra-TAD connectivity was observed during DN2-to-DN3 and DN4-to-DP transitions, coinciding with major changes in chromatin accessibility and compartmentalization, as described above. Globally, increased or decreased intra-TAD connectivity during each of the HSC to DP transition states strongly correlated with gene upregulation or downregulation, respectively. Importantly, architectural reorganization within TADs usually preceded transcriptional activation of associated genes, suggesting that pre-establishment of chromatin contacts generates a permissive topology for gene activation $(39,72,73)$.

During thymocyte development, transcriptional regulation of CD4/CD8 coreceptors is concomitantly linked with cell-fate choice toward either the helper or cytotoxic lineage $(10,74-$ 76). Both murine $C d 4$ and $C d 8$ loci undergo 3D reorganization that involves stage-specific chromatin contacts between $C d 4$ and $C d 8$ promoters with various proximal and distal RE (77). In DN thymocytes, $C d 4$ activation is prevented by a chromatin loop between an upstream E4p enhancer and a silencer located $3 \mathrm{~kb}$ downstream of the TSS (78), mediated by RUNX1 and P-TEFb (79). However, in DP and CD $4^{+}$cells, this chromatin interaction is dissolved and new ones are established between the $C d 4$ promoter and the E4p enhancer (in DP stage) and/or another proximal enhancer E4m located $\sim 2 \mathrm{~kb}$ downstream of the TSS (in $\mathrm{CD}^{+}$cells) leading to the initial activation and further upregulation of $C d 4$ during these transitions $(80,81)$.
These new activating chromatin contacts are mediated by RUNX1 and other transcription factors, such as E2A and TCF-1. Dynamic chromatin interactions have been also reported around the $C d 8$ locus, which is composed by the $C d 8 \alpha$ and $C d 8 \beta$ genes, showing the same transcriptional orientation but separated by $36 \mathrm{~kb}$. In murine $\mathrm{CD}^{+}$cells, the expression of $\mathrm{Cd} 8$ locus is regulated by six different enhancers through stage-specific enhancer-promoter (E-P) interactions and mediated either by IKAROS and BAF complex in DP cells or ThPOK in $\mathrm{CD}^{+}$cells (82). These chromatin contacts are significantly lower in B cells, where $C d 8$ locus is inactive (83). Further functional validation (e.g. deletion/mutation of enhancers) will help to elucidate the role of each regulatory contact in the control of transcription and thus cell fate.

As well as the intrachromosomal E-P interactions reported in $C d 4$ and $C d 8$ genes, long intrachromosomal interactions have also been documented between these two loci in murine DP and $\mathrm{CD}^{+}$cells, but not in $\mathrm{DN}$ and $\mathrm{CD} 4^{+}$cells. The stage-specific, interchromosomal association between these genes was also confirmed by $3 \mathrm{D}$ DNA FISH in humans where $C d 4$ and $C d 8$ genes are located on chromosomes 12 and 2 respectively (55). The conservation of the $C d 4-C d 8$ interaction in murine and human $\mathrm{T}$ cells highlights the significance of the $3 \mathrm{D}$ chromatin organization in coordinating transcriptional regulation of genes, which not only defines the stochastic CD4/CD8 lineage commitment but also directly control the immune responses.

Although the majority of $3 \mathrm{D}$ genomic studies in $\mathrm{T}$ cell development were conducted in murine models, a study in human primary resting $\mathrm{CD}^{+}$cells started unraveling the principles of $3 \mathrm{D}$ chromatin organization around active enhancers and promoters by applying ChIA-PET technology with antibody against the active histone mark H3K4me2 (84). This study identified a total of 6520 E-P connections, the majority of which were short-range (56\%) and independent of CTCF binding (81\%), indicating the implication of other possible genome organizers, such as TFs (SATB1, ETS, RUNX and GATA) or transcriptional coregulators (see Chapter IV). Interestingly, extensive long-distance E-P interactions, were also reported for Vav1 and Runx1 genes, both regulators of thymocyte development and TCR signaling cascade. In the same study, the global mapping of the long-range interactions in chromosome 19 (known to contain a rich network of multiple enhancer and promoters) showed five distinct chromatin domains enriched with "local" interactions from $20 \mathrm{~kb}$ to hundreds of $\mathrm{kb}$, while these domains were interconnected by super long-distance interactions, indicating multiple and complex layers of $3 \mathrm{D}$ chromatin organization in human $\mathrm{CD} 4^{+}$ cells (84).

In conclusion, major architectural reorganization occurs during various steps of $\mathrm{B}$ and $\mathrm{T}$ cell development, involving A/ $\mathrm{B}$ compartment switches, changes in intra-TAD interactions and dynamic establishment or loss of chromatin contacts in cis and in trans. Although many of these topological changes associate with transcriptional activation or silencing, functional perturbations will be critical for dissecting the temporal interconnections and cause-and-effect relationships between the two processes. 
Notably, the various transitions during the step-wise B or T cell development are characterized by different degrees of global chromatin reorganization, with the most striking changes coinciding with key checkpoint transitions, such as DN2-DN3 $(39,85)$. Whether this major topological rewiring is critical for irreversible "locking" of cell identity or solely a consequence of other major molecular and cellular changes, such as global chromatin opening and increased proliferation capacity, remains to be shown.

\section{CHAPTER III: CHROMATIN REORGANIZATION UPON B/TCR ACTIVATION}

One of the most interesting key features of lymphopoiesis emerges from the multitude of transitions between resting and proliferative phases during which lymphocytes modulate their global transcription levels, metabolic activities and cytokine production (86-90). These changes are also accompanied by dramatic remodeling of chromatin accessibility and $3 \mathrm{D}$ architecture along with a change of nuclear volume. Before antigen encounter, both naive $\mathrm{B}$ and $\mathrm{T}$ cells constitute quiescent populations endowed with a very dense and compacted chromatin accompanied by long-range, intrachromosomal interactions (84, 91). Of note, in $\mathrm{T}$ cells this highly compacted chromatin state, which is mediated by the condensin II complex, is also critical to prevent premature or aberrant signal activation by blocking Stat5 access to its genomic targets (92). TCR activation leads to a rapid and dramatic enlargement of the nuclei from $4-5 \mu \mathrm{m}$ diameter in the murine naive $\mathrm{CD}^{+}$to $10-12 \mu \mathrm{m}$ diameter in $\mathrm{TH} 1$ and $\mathrm{TH} 2$ cells, as shown by confocal and transmission electron microscopy experiments in vitro (92-94). A similar massive nuclear expansion accompanied by Myc- and ATP-dependent chromatin decondensation is observed upon BCR activation of naive B cells by IL4 and LPS, as observed by super resolution microscopy (95). Additionally, ${ }^{14} \mathrm{C}$ incorporation and micrococcal nuclease (MNase) experiments demonstrated a concomitant global increase of histone acetylation, chromatin accessibility and transcriptional activity $(88,95)$ as well as a significant and gradual DNA hypomethylation when profiling activated B cells for whole genome bisulfite sequencing (WGBS) (96).

\section{B Cells}

GC B cells: Hi-C analysis on human B cells, revealed a multilayer 3D chromatin reorganization upon the transition from naive to GC B cells including: an increased promoter connectivity and enhancer interactivity, 5' to 3' GC gene looping and merging of gene neighborhoods marked by active histone modifications (97). Genomic regions with increased interactivity were associated with dense binding of SPIB, PU.1 and EP300, the role of which in $3 \mathrm{D}$ chromatin organization remains to be elucidated. Loss of TAD boundaries were more frequent than gains and led to the transformation of "Gene neighborhoods" $(30,98)$ into larger and de novo "Gene cities" (97).
One of the most striking examples of chromatin remodeling and $3 \mathrm{D}$ rewiring during the $\mathrm{GC}$ transition occurs around the $\mathrm{Bcl} 6$ locus, which encodes for a master regulator of GC reaction. A $114 \mathrm{~kb}$ long, distal Bcl6 enhancer cluster, which functions as a Locus Control Region (LCR), undergoes dramatic epigenetic alternations, including chromatin opening, binding of critical TFs and cofactors [such as OCT2 and OCA-B (99)], gain of $\mathrm{H} 3 \mathrm{~K} 27 \mathrm{ac}$ and increase in transcriptional activity. In parallel, the LCR establishes a large number of de novo and strong interactions with $B c l 6$ promoter and other nearby genes forming a highly interacting hub. More specifically, OCA-B was shown to directly recruits Mediators, bridging the BCL6 LCR to the BCL6 promoter in cis (99). Although the exact organizational principles and regulatory properties of this hub remain to be fully elucidated, deletion of the Bcl6 LCR in mice resulted in the abrogation of the GC formation beyond the regulation of Bcl6 per se (97).

A recent study demonstrated that in B cells, the naive to GC transition is also characterized by compartmentalization changes and the emergence of a new type of weak, Intermediate (I) compartments, which allow for inter-compartment interactions. I compartments in GC B cells arise from A or B compartments and are enriched for the $\mathrm{H} 3 \mathrm{~K} 27 \mathrm{me} 3$ mark, containing genes repressed by the PRC (29).

Plasma cells: The GC transition to plasmablasts (and further to long-lived plasma cells) is characterized by a major chromatin reorganization harboring a typical cartwheel-like structure as defined by Cajal and Marschalko (100). The silencing of Pax5 expression at this stage was proposed to be responsible for overwriting the typical B cell transcriptional program and 3D chromatin organization (60), although only minimal compartment changes were identified. Indeed, plasma cells have been shown to retain a high fraction of I compartments (29), irreversibly locking the 3D chromatin organization.

A number of recent studies have started to shed light into the extent and principles of $3 \mathrm{D}$ chromatin reorganization upon naive $\mathrm{B}$ cell activation in vitro, using various stimuli and timepoints after activation. Activation of murine naive B cells with IL-4 and LPS for $24 \mathrm{~h}$ led to very few changes in compartments and boundaries, but showed a significant shift from long-range to short-range interactions as demonstrated by in situ $\mathrm{Hi}-\mathrm{C}$ and ChIA-PET experiments (91). There was also a substantial increase in the number and strength of CTCF-mediated E-P loops and increased binding of cohesin at loop anchors (95). Similarly, a recent study using a genome-wide tethered chromosomal conformation capture analysis (TCC) on murine LPS-activated plasmablasts (101), identified a higher number of short intrachromosomal interactions $(<10 \mathrm{Mb})$ in comparison to naive B cells. Moreover, this study also described a number of interchromosomal interactions that were preferentially enriched for genes associated with the plasma cell fate such as $\operatorname{Prdm} 1$ and $\mathrm{Xbp} 1$.

More recently, a study tracked the dynamic transcriptional and architectural changes from the very early time points after LPS activation of murine naive B cells until their differentiation into antibody-secreting plasma cells (102). The authors reported 
that early transcriptional changes (3hr post-activation) precede genomic reorganization, suggesting either the pre-existence of a permissive configuration with an instructive role of transcription in $3 \mathrm{D}$ chromatin reorganization or a partial uncoupling of the two processes. In situ Hi-C analysis uncovered two major waves of 3D chromatin changes: before the first cell division (at late G1 phase) and upon plasmablast differentiation. As previously reported, no major chromatin changes were uncovered at the compartment nor at the TAD levels. Most changes involved stage-specific loss or gain of long-range E-P interactions $(<1 \mathrm{Mb})$ around gene loci relevant for each transition, including Bcl6, Ell2 and Pax5. Intriguingly, conformational changes that occurred in the first wave were largely preserved during clonal expansion despite multiple rounds of mitosis, during which chromatin architecture (including compartments, TADs and loops) is lost $(103,104)$. This suggests that the B cell transcriptional program and topology are faithfully reestablished during each division, although the underlying mechanisms remains unclear. The second wave of genome reorganization occurs during a prolonged G1 phase linked to plasma cell differentiation, highlighting the importance of this time window both for architectural changes and cell fate decisions, as reported in other systems (104-106).

Memory B cells: The dynamic changes in chromatin state and conformation landscape that occurs upon B cell activation and GC transition are largely reversible as cells progress to the memory stage. The epigenetic landscape, transcriptome, chromatin accessibility and 3D organization of quiescent human naive and memory $B$ cell populations are indeed indistinguishable upon unsupervised clustering, nonetheless clearly separated from GC and plasma mature B cells populations (29). Most of I compartments defined in GC B cells, switch back upon memory B cell transition to a compartment organization similar to naive B cells, erasing this layer of 3D organization imprint and allowing memory B-cells priming for GC re-entry. In contrast to all of these multi-omics characterizations, DNA methylation and $\mathrm{H} 3 \mathrm{~K} 27 \mathrm{me} 3$ profiles clearly separate memory from naive B cells, indicating that the epigenetic state of memory B cells is only partially reversed to a naive-like configuration. Together, these epigenetic and topological features might be critical for the ability of memory $\mathrm{B}$ cells to rapidly re-enter GC reaction and differentiate into plasma cells upon secondary infection $(107,108)$.

\section{T Cells}

Multiple studies using 3D DNA-FISH and 3C assays described various degrees of topological reorganization during $\mathrm{T}$ cell activation and differentiation towards $\mathrm{T}$ helper lineages (TH1 or TH2). For example, specific genes encoding important effectors and cytokines of the opposite lineage (e.g. c-Maf and Il-4 in TH1 cells and Ifng in TH2 cells) have been reported to relocate towards heterochromatic compartments $(109,110)$. This subnuclear repositioning is linked to gene silencing, supporting $\mathrm{TH}$ polarization and sub-lineage specification. Architectural changes linked to upregulation of gene expression upon TCR activation were also described early on. 3C experiments showed that binding of transcription factors STAT3 and NFATc2 factors mediate E-P looping around the Il-21 locus (111), promoting the transcriptional activation of this significant pleiotropic cytokine that acts as a regulator of inflammation and immune responses. Additionally, an extremely long-range intrachromosomal interaction $(\sim 98.5 \mathrm{Mb})$ that brings the promoter of IfngR1 gene proximal to Ifng (master regulator of the TH1 differentiation) promoter and its downstream RE was observed in murine $\mathrm{CD}^{+}$and $\mathrm{TH} 1$ cells. This interaction occurred in a monoallelic fashion in agreement with the monoallelic expression of these genes, while it was absent in $\mathrm{TH} 2$ cells, where none of these genes are expressed (112). Finally, an example of interchromosomal association has been documented in murine $\mathrm{CD} 4^{+}$cells between the Th2 locus that contains interleukin 4 (Il4), interleukin 5 (Il5) and interleukin 13 (Il13) genes located in a single gene cluster on chromosome 11 and the TH1 cytokine interferon gamma (INF- $\gamma$ ) located on chromosome 10. This physical interaction between these loci presents a "poised" chromatin conformation and precedes the $\mathrm{T}$ cell effector fate decisions. Upon TCR activation, select cytokine genes dissociate from this hub in order to be expressed, enabling polarization either towards the $\mathrm{TH} 1$ or the $\mathrm{TH} 2$ fate (72). In the past years, several studies started revisiting the $3 \mathrm{D}$ chromatin reorganization upon $\mathrm{T}$ cell activation using technologies that allow quantitation on a genome-wide scale. A recent study in human $\mathrm{CD}^{+}$reported that upon $24 \mathrm{~h}$ of TCR activation, about $30 \%$ of long-range chromatin interactions undergo significant changes, while compartments or TADs remain unaffected (113). In agreement, another study combining ATAC-seq, in situ $\mathrm{Hi}-\mathrm{C}$ and RNA-seq in human $\mathrm{CD}^{+}$and $\mathrm{CD}^{+}$cells before and after in vitro TCR stimulation for $72 \mathrm{~h}$, reported only minimal changes in compartmentalization. Specifically, less than $4 \%$ of the genome switched from A-to-B compartment along with their respective transcriptional changes (114). However, the same study reported significant differences at the sub-megabase level with the emergence of new and stronger boundaries that partitioned TADs into smaller and more numerous subdomains when compared to naive T cells. Moreover, TCR activation led to formation of de novo short-range chromatin loops, resulting in increased intra-TAD connectivity in more than $60 \%$ of TADs in both $\mathrm{CD}^{+}$and $\mathrm{CD}^{+}$cells. The establishment of new chromatin contacts coincides with increased chromatin accessibility around regions that contain binding motifs for transcription factors related to $\mathrm{T}$ cell development and differentiation $(114,115)$. On the other hand, the observed strengthening of TAD borders was found to be coupled with reduced chromatin accessibility, higher nucleosome occupancy and low levels of gene expression. Importantly, this topological reorganization and transcriptional reprogramming upon TCR activation was largely restricted to genes relevant for immunity. The dynamic changes in the chromatin interactions upon TCR activation were also recently reported by several other groups, based on promoter capture $\mathrm{Hi}$ $\mathrm{C}$ (PCHi-C) and Trac-looping experiments, demonstrating that these promoter interactomes were lineage-specific and associated with target gene expression (116-118). All studies indicated rewiring on E-P chromatin interactions, global changes in 
chromatin accessibility and histone modifications (H3K27ac, H3K4me1, H3K4me3), when compared to naive T cells.

So far, only few studies on chromatin organization in $\mathrm{T}$ helper cells have been reported. In 2017, two different reports described the genome organization in murine $\mathrm{TH} 2$ and human TH17 cells $(38,119)$. 3eHi-C experiments in murine TH2 cells identified a total number of 1,363 TADs and CTCF binding sites were found not only at the TAD borders but also interspersed on enhancers within TADs. Knock-down of CTCF expression led to significant downregulation and cell-to-cell variation of immune related genes, while deletion of specific intra-TADs CTCF binding sites led to compromised E-P interactions (38). These experiments support an important role of CTCF in stabilizing E$\mathrm{P}$ contacts and controlling cell-to-cell fluctuations of gene expression. The same study reported that within TADs, long range E-P interactions mostly involved genes critical for immune function and $\mathrm{T}$ cell activation, suggesting that transcription of lineage-specific genes depends on physical communication with distal enhancers, while housekeeping genes mostly rely on proximal regulatory elements (38).

Comparison between four different subsets of $\mathrm{T}$ cells (bulk $\mathrm{CD}^{+}$, naive $\mathrm{CD}^{+}$, TH17 and Tregs using either PCHi-C or $\mathrm{H} 3 \mathrm{~K} 27 \mathrm{ac} \mathrm{HiChIP})$ revealed cell type-specific loops upon differentiation that might contribute to the unique identities and functions of $\mathrm{T}$ cell subsets (119). Differentiation of naive $\mathrm{CD}^{+}$cells into TH17 cells or regulatory $\mathrm{T}$ cells $\left(\mathrm{T}_{\text {regs }}\right)$ creates subtype-specific E-P interactions between regions with similar DNA accessibility as shown by $\mathrm{H} 3 \mathrm{~K} 27 \mathrm{ac} \mathrm{HiChIP}$ on primary human T cells. Genes within cell-type-specific E-P loops encode for canonical $\mathrm{T}$ cell subtype TF and effector molecules, further supporting the potential regulatory impact and biological significance of these interactions. Moreover, the anchors of cell-type specific H3K27ac HiChIP loops enriched for binding of TF known to drive T cell subtype differentiation, suggesting a role of these TFs on the loop formation (119).

In conclusion, all abovementioned studies started unraveling the principles of $3 \mathrm{D}$ reorganization during both $\mathrm{T}$ and $\mathrm{B}$ cell lineage commitment and differentiation. In both lineages, major structural changes in A/B compartments are observed, while $\mathrm{TAD}$ size and numbers are largely conserved throughout the process with the exception of B/TCR activation, which leads to extensive TAD boundary alterations. Loss of boundaries causes TAD fusion in GC cells whereas the acquisition of de novo and stronger boundaries led to TAD partitioning in activated T cells. Moreover, $\mathrm{B}$ and $\mathrm{T}$ cell activation is accompanied by an increase of intra-TAD connectivity especially around genes relevant for lymphoid identity and function. During B/T lymphocyte development and differentiation, studies reported increased long and short cis chromosomal interactions, while during $\mathrm{T}$ cell development and $\mathrm{TH}$ polarization inter-chromosomal interactions have also been observed and linked to transcriptional changes around critical $\mathrm{T}$ cell regulatory genes. These trans interactions, but also a large percentage of cis E-P loops in T cell lineage are independent of CTCF binding, highlighting the need for investigating other nuclear proteins and mechanisms for their roles in shaping $3 \mathrm{D}$ genome folding in lymphocytes.

\section{CHAPTER IV: PRESUMED MECHANISMS AND PLAYERS OF 3D CHROMATIN REORGANIZATION DURING B/T LYMPHOPOIESIS}

In the previous chapters, we discussed the global and local 3D chromatin conformation changes that occurs during lymphocyte specification as well as activation and differentiation. What are the forces and critical players that drive this topological rewiring?

There are several well-described mechanisms and architectural factors that actively drive different layers of 3D genomic organization, as extensively reviewed in multiple recent papers (120-124). In mammalian cells, CTCF/Cohesin-mediated loop extrusion $(121,125)$ is shown to be responsible for the formation of most chromatin loops and TADs/subTADs, since degradation of any of these architectural components causes drastic changes in chromatin topology and variable -rather moderate- effects on gene expression (126-130). On the other hand, increased "self-attraction"/affinity among chromatin loci with similar transcriptional and chromatin states, such as homotypic histone modifications and TF/cofactors is important for compartmental segregation and the emergence of droplet-like, phase-separated, membraneless organelles, such as nucleoli or nuclear speckles (131-134).

A large number of cell-type specific TFs $(135,136)$ and transcriptional-cofactors (e.g. BRD4, PRC2, Pol II) (134, 137139) have been reported to form large nuclear condensates, which may mediate activating or repressive chromatin contacts and hubs in a loop-extrusion independent manner. Moreover, TFs have been reported to mediate long-range chromatin contacts through direct homodimerization (e.g. YY1) or protein-protein interactions with other bona fide architectural factors, such as cohesin or PRC2 components (120, 140-143). Importantly, the expression and/or genomic distribution of many of these critical factors (TFs and histone modifications) change during $\mathrm{B}$ and $\mathrm{T}$ cell development and activation, therefore they might contribute to the observed 3D chromatin reorganization.

Below, we will discuss key findings that support the roles of $\mathrm{CTCF} /$ cohesin and select TFs in stage-specific 3D architecture during lymphopoiesis. Given that these mechanisms have been recently reviewed elsewhere (VDJ and TF reviews) (144-146), we will focus on two less appreciated proteins and structures (histone linker and nuclear lamina) that play important roles in the regulation of $3 \mathrm{D}$ nuclear organization of $\mathrm{B}$ and $\mathrm{T}$ cells.

\section{CTCF/Cohesin-Mediated Loop Extrusion}

The loop-extrusion mechanism describes the progression of chromatin through the cohesin ring and the stabilization of loops when the ring encounters convergent CTCF sites. In the context of lymphocyte biology, CTCF/cohesin complex was reported to mediate long-range chromatin interactions that control stage-specific transcription of various cytokine and other critical genes (Ifng, Il21, MHC-II etc.) during $\mathrm{B} / \mathrm{T}$ lymphocyte development and differentiation (111, 147-152). 
One of the most striking and well-studied examples of chromatin looping through $\mathrm{CTCF} /$ cohesin extrusion is the $\mathrm{V}(\mathrm{D}) \mathrm{J}$ recombination in developing $B$ cells $(66,153-156)$. This ensures recombination of any of the $113 \mathrm{VH}$ segments with any of the 13 $\mathrm{DH}$ and $4 \mathrm{JH}$ segments and thus, generation of an extremely diverse repertoire of antigen receptors. This process, which has been extensively reviewed recently $(157,158)$, occurs through a number of highly regulated steps and loops, which are dependent on cohesin factors and multiple CTCF binding sites $(159,160)$ resulting in a remarkable contraction of the entire ( 2.75 Mb) Igh locus (161). Similar CTCF and cohesin-dependent loop extrusion mechanisms mediate $\mathrm{V}(\mathrm{D}) \mathrm{J}$ recombination at the Tcr loci in T cells. The creation of a developmentally regulated chromatin hub supports $\mathrm{V}_{\alpha}-\mathrm{J}_{\alpha}$ synapsis and eventually leads to a successful V(D)J recombination (156, 162, 163). Deletion of a specific CTCF binding site (named EACBE), causes merging of the subTAD domains, reduction of long-range chromosomal interactions between the $\mathrm{V}_{\alpha}$ and $\mathrm{J}_{\alpha}$ segments and leads to impaired Tcra rearrangement (164).

Genetic knock-out or protein degradation experiments in cell lines and mouse models further support the critical roles of CTCF and Cohesin in lymphocyte development. Specifically, it was recently shown that CTCF is required for proper control of the transcriptional program and high proliferation rate of GC B cells and its depletion results in premature differentiation into plasma cells (165). On the other hand, genetic ablation of Ctcf in mouse thymocytes leads to cell cycle arrest, while deletion of CTCF binding sites results in increased cell-to-cell variation of gene expression, indicating a fundamental significance of these long-range E-P interactions in stabilizing gene expression in mammalian T cells $(38,166)$. CTCF/cohesin complex binding is also highly enriched at enhancers and in particular "superenhancers" in murine thymocytes, mediating long-range communication with target genes (167). In the same study, it was also reported that cohesin facilitates enhancer clustering in thymocytes, while its conditional deletion results in weakened enhancer-enhancer interactions and downregulation of the associated genes.

Interestingly, transcription and $3 \mathrm{D}$ chromatin organization can also be maintained in a cohesin-independent manner. Indeed, using PCHi-C in a CTCF or Cohesin auxin-inducible degron (AID) system to assess the rewiring of promoteranchored loops, Thiecke et al. showed that while a majority of promoter contacts are lost, a significant number of them are actually constrained and maintained by TAD boundaries or even gained. Cohesin-independent interactions were mainly centered on active promoters or active promoters and enhancers but remained affected by transcription modulation (168). These results mirror the minimal impact of cohesin depletion on enhancer activity and transcriptional control in steady state conditions (126-129). Nonetheless, cohesins were shown to be crucial for macrophage-induced inflammatory response of HSPC (169) arguing for a role of these genome organizer in cell fate transition. While genetic and epigenetic mechanisms enabling cohesin-independent looping are not completely understood, the role of several chromatin co-factors involved in phase condensates such as mediators and $\operatorname{Brd} 4$ has been recently addressed. Using a SMASh tag degron system, El Khattabi et al. were able to discriminate essential from non-essential mediators in $\mathrm{T}$ and $\mathrm{B}$ lymphocytes based on their capacity to affecting Pol $\mathrm{ll}$ recruitment to the chromatin (170). In situ $\mathrm{Hi}-\mathrm{C}$ and ChIA-PET profiling MED14-depleted B-cells demonstrated that Mediator complex is largely dispensable for E-P looping. Similarly, E-P loops are not drastically affected by the inhibition/ degradation of the chromatin insulator $\operatorname{Brd} 4$ nor by phase condensate dissolution in a B-ALL cell line (73), conversely to widespread transcription and chromatin decompaction.

\section{Lineage-Specific Transcription Factors}

Lymphopoiesis is controlled by a number of lineage-specific TFs, which orchestrate stage-specific transcriptional and chromatin alterations, including changes in chromatin accessibility, DNA methylation, histone modifications, and ultimately 3D chromatin organization. Critical lineage regulators, such as Ebf1 in B cells $(171,172)$ and Tcf1 in T cells (173), have been reported to act as pioneer factors capable of binding previously inaccessible genomic regions and inducing local chromatin opening. According to these studies, recruitment of epigenetic modulators and cofactors will then lead to additional epigenetic remodeling including erasure of repressive marks (e.g. H3K27me3 and DNA methylation) and deposition of active histone modification, which coincides with activation of lineage-specific genes. In parallel with the TF-mediated changes in chromatin accessibility, state and activity, a lot of recent studies support functional links between TF binding and $3 \mathrm{D}$ chromatin reorganization during cell fate transitions, such as reprogramming $(45,174)$, differentiation $(175,176)$, or tumorigenesis (177) and started shedding light into the temporal dynamics and underlying mechanisms. Protein oligomerization and interactions with loop extruders or nuclear landmarks (nuclear lamina) are some of the proposed mechanisms by which TFs might mediate chromatin looping, such as E-P interactions, as shown for example for YY1, KLF4 $(45,141,178,179)$. Alternatively, TFs might promote long-range contacts by biomolecular condensation through low-affinity multivalent interactions non-coding RNAs and other protein factors (e.g. BRD4, p300 and Mediator complex) via their intrinsically disordered regions (IDRs) $(120,180)$. Finally, TF binding might indirectly contribute to $3 \mathrm{D}$ reorganization by inducing changes in chromatin states and thus altering compartmental segregation.

A large number of key lineage TF and protein cofactors in B/T lymphocyte development have been proposed to mediate chromatin reorganization and DNA looping as recently reviewed (77, 145, 181-183), although functional validations and mechanistic insights of their proposed architectural function are often missing. Below, we discuss some of the beststudied examples:

Special AT-rich binding protein 1 (SATB1) is a T cell enriched transcription/epigenetic factor critical for thymocyte development and differentiation. Multiple studies support the role of SATB1 also as 3D genome organizer by mediating specific chromatin loops, contributing to a complex protein scaffold that 
forms an "aromatic" or "cage like" structure, known as "loopscape". The loopscape circumscribes heterochromatin away from euchromatin by tethering distant genomic loci into its network, facilitating their coordinated transcriptional regulation (184-187). The most well documented loopscape example has been reported for the $M H C$ locus, where SATB1 interacts with promyelocytic leukemia (PML) protein in order to organize the locus into distinct higher-order chromatin-loop domain structures. Silencing of either SATB1 or PML leads to dynamic reorganization of chromatin loops affecting the expression of the MHC class I genes (54). SATB1 was also shown to play a critical role in the control of Tcra locus rearrangements through RAG regulation (188). In DP thymocytes, the highly expressed SATB1 binds to the anti-silencer element (Ase) and to the distant Rag1 and Rag2 promoters, mediating the formation of a chromatin hub. The latter facilitates RNA polymerase II recruitment and leads to activation of Rag genes. Genetic depletion of Satb1 leads to a reduction of RNA Pol II recruitment and transcriptional activation, eventually causing a defective $\mathrm{V}(\mathrm{D}) \mathrm{J}$ recombination during thymocyte development. Additionally, in TH2 differentiated cells, SATB1 has been shown to function as anchor for the formation of dense small loops around the Th2 gene locus leading to the activation of all cytokine genes (Il4, Il5 and Il13) that are harbored in the locus (185).

BCL11B is a zinc finger TF that function as a key developmental regulator of cellular differentiation in the T-cell lineage $(39,189-191)$. BCL11B is considered as a T cell-specific genome organizer that maintains the $\mathrm{T}$ cell nucleome and mediates the formation of DNA loops during thymic $\mathrm{T}$ cell development. BCL11B is highly expressed upon DN2 to DN3 transition leading to de novo genomic E-P interactions. Deletion of $\mathrm{Bcl11b}$ in $\mathrm{CD}^{+}$cells led to a decrease in E-P interactions suggesting that even in late $\mathrm{T}$-cell developmental stages the topologically interacting DNA loops are BCL11B-mediated (39). Although most of the studies have shown the role of BCL11B during $\mathrm{T}$ cell development, few groups have also documented its role in later stages of $\mathrm{T}$ cell differentiation. BCL11B binds to RE of critical genes such as $\mathrm{Il}-4$ (silencer), Runx3 (enhancer) and Gata3 (promoter) during TH2 cells differentiation. This binding facilitates and stabilizes the TH2 lineage fidelity indicating structural roles of this factor in the regulatory loops/network upon T cell activation (192).

Yin Yang 1 (YY1) is known as a transcriptional activator or repressor and contributes to chromosome organization through mediating interactions between active E-P loops in several cell types $(141,193)$. Genetic ablation of its binding sites or depletion of YY1 protein leads to disrupted loops and gene expression. YY1 has a pivotal role during B cell development and lymphoma (194), with the most well characterized chromatin loop example reported for the Igh locus (195). 3D DNA FISH and 3C experiments showed that YY1 controls the Ig class switch recombination, via bridging the Igh intron with the $3^{\prime}$ regulatory region ( $\left.3^{\prime} \mathrm{RR}\right)$ located at the end of the Igh locus. Additionally, YY1-mediated loops have also been reported for Th2 locus during TH2 differentiation, where YY1 knock down $\mathrm{TH} 2$ cells presented decreased intrachromosomal interactions as shown by $3 \mathrm{C}$ experiments (196).
Paired Box 5 (PAX5) is a TF that has a dual role in activating the $B$ cell program while preventing expression of non-B cell genes (197). The role of Pax5 in maintaining global 3D genome organization in $\mathrm{B}$ cells was recently investigated by a study that combined Hi-C and Pax5 ChIP-seq profile of WT and Pax $5^{-/-}$ Pro-B (60). While no major changes in compartmentalization nor TAD numbers were uncovered in $\mathrm{Pax} 5^{-/-}$pro-B cells, Pax5 loss associated with local chromatin reorganization (strengthening or weakening of loops) at specific loci, including the Igh locus, where Pax5 binds at distal $\mathrm{V}_{\mathrm{H}}$ regions. This is in agreement with a previous study, which documented that Pax 5 deletion in pro-B leads to preferential usage of the $4 \mathrm{~V}_{\mathrm{H}}$ segments, loss of long-range interactions within the $I g$ locus TADs and overall abrogation of Igh locus organization (198). Intriguingly, re-expression of $\operatorname{Pax} 5$ in $\mathrm{Pax} 5^{-/-}$pro-B showed a partial rescue of the observed topological changes, indicating that this TF is necessary but not sufficient to establish and maintain the genome organization in developing B cells. In further support to this notion, Pax5 ectopic expression in T-cells, was insufficient to induce Igh locus contraction. Intriguingly, restoration of chromatin interactions in Pax5-rescued pro-B was not impaired upon treatment with the RNA Pol 11 inhibitor $\alpha$ amanitin, suggesting that the role of Pax5 in 3D organization is largely independent of its function as transcriptional regulator (198).

\section{Linker Histones}

Dynamic changes in chromatin state may also induce 3D architectural changes either through the differential affinity between homotypic or heterotypic histone modifications or through protein-protein interactions among the recruited epigenetic readers (121, 123, 129, 199, 200). Although, literature has mainly focused on core histones and their modifications, two recent studies started shedding light into the role of $\mathrm{H} 1$ linker histones in local and global chromatin architecture, in the context of B and T cell biology $(201,202)$. Using a triple conditional knock out (cTKO) for Histone 1 isoforms c/d/e, Willcockson et al. specifically depleted $\mathrm{H} 1$ in murine $\mathrm{T}$-cells and uncovered a de-repression of $\mathrm{T}$-cell activation genes along with chromatin decompaction, reminiscent of $\mathrm{T}$-cell activation. Hi-C analysis of $\mathrm{CD} 8^{+}$cells indicated that Histone 1 binding drives chromatin compaction not only within $\mathrm{B}$ compartments, but also within a subset of $\mathrm{A}$ compartments that are enriched for PRC2 binding. To which extent the latter could represent I compartments, similar to the ones described in activated B cells (29) remains to determined. Loss of $\mathrm{H} 1$ either in $\mathrm{B}$ or $\mathrm{T}$ lymphocytes was also shown to induce a profound reprogramming of epigenetic states with an expansion of $\mathrm{H} 3 \mathrm{~K} 36 \mathrm{me} 2$ deposition at the expense of $\mathrm{H} 3 \mathrm{~K} 27 \mathrm{me} 3$, suggesting that $\mathrm{H} 1$ binding plays an active role in balancing these modifications (203). Deletion of H1c and H1e in murine GC B cells conferred enhanced fitness and self-renewal, while at the molecular level inducing large-scale, but focal, chromatic decompaction and de-repression of stemness signature gene (202). Accordingly, Hi-C analysis revealed thousands of B-to-A compartment switches, which mostly 
represented expansion of A compartments, coinciding with spreading of H3K36me2. The above studies unravel novel and intricate functions of $\mathrm{H} 1$ linker histones in regulating $3 \mathrm{D}$ chromatin organization, epigenetic states and transcriptional activity that go beyond B/T cell biology (204).

\section{Nuclear Lamina}

Nuclear Lamina (NL) serves as a scaffolding deck for heterochromatin, shaping chromatin compartmentalization and regulating gene silencing (205). Alterations in the NL compartment have been also reported upon lymphocyte activation. As shown by early electron microscopy studies, resting lymphocyte present a compact heterochromatin at the nuclear periphery which dissociates upon activation and gene expression (90, 206-208).

In lymphocytes, tethering of gene loci on $\mathrm{NL}$ and their repositioning towards the nuclear center is considered as a safety mechanism to prevent lymphocyte premature activation or recombination (209-211). For example, localization of $I g$ loci at the NL in pre-pro-B cells, prevents access by RAG proteins, impeding premature $\mathrm{V}(\mathrm{D}) \mathrm{J}$ recombination, while their release from the NL in pro-B cells constitutes a major event enabling B cell fate and proper BCR expression (209). Moreover, while proximal $\mathrm{V}, \mathrm{D}$ and $\mathrm{J}$ sequences are released from the NL in pro-B cells, distal V segments remain lamin-associated, ensuring the spatiotemporal control of antibody repertoire diversity. Relocalization from NL has also been shown in the context of $\mathrm{T}$ cell activation. Upon TCR activation, T cell-specific genes and their enhancers are repositioned from LAD-associated subcompartments, to TAD-proximal subcompartments, although they still remain in a proximity to the nuclear periphery $<0.6 \mu \mathrm{m}$ (210). This "constrained release" mechanism contributes to a fast transcriptional response upon $\mathrm{T}$ cell activation, that is lost when specific $\mathrm{T}$ cell genes and enhancers relocate towards the permissive perinuclear domains. Another example of repositioning from the nuclear periphery in $\mathrm{T}$ cells was shown for the BCL11B genome organizer (211). During thymic T cell development in DN2 cells, a long non-coding RNA named thymocyte differentiation factor (ThymoD) promotes the demethylation of CTCF bound sites and activates cohesin-dependent looping to juxtapose the $B c l 11 b$ enhancer and promoter into a single-loop domain leading to $B c l 11 b$ expression (211).

Despite the strong association of nuclear periphery with heterochromatin and gene silencing, there are a few relevant and noteworthy exceptions of gene expression. 3D-immuno DNA/RNA FISH experiments in plasma cells revealed that the transcribed $I g h, k$ and $j$ genes (located on chromosomes 12, 6 and 5 respectively), are spatially clustered at the nuclear periphery with RNA polymerase II transcription factories (212). These Ig genes are not localized to the NL but close to nuclear pore and reticulum endoplasmic, in support of the previously proposed 'gene gating theory' (213). This process has been suggested to facilitate Ig mRNA export and maximize the antibody production process. Active transcription at the nuclear periphery of lymphocytes was also reported for immune-specific microRNA genes (miR-181a1b1, miR-181a2b2, miR-181c, miR-142, miR-146a, miR-17-92 and miR-155) during $\mathrm{T}$ cell development (93). These genes are located within the constitutive inter-LADs (ciLADs), while their peripheral position is conserved throughout development (from ESCs to thymocytes, $\mathrm{CD}^{+}$and $\mathrm{TH}$ cells). Moreover, ChIP-seq analysis showed that microRNA genes are occupied by NUP153/93 and DROSHA proteins, suggesting spatial links among transcription, post-transcriptional processing and nuclear export (93).

The importance of nuclear lamina for LAD organization together with the strong association between LADs and B compartments, argue for the potential function of NL for proper chromatin compartmentalization. To address this question, a recent study deleted Lamin $\mathrm{B}$ receptor $\left(\mathrm{LBR}^{-/-}\right)$in thymocytes and tracked changes in nuclear organization by imaging and compartmentalization by Hi-C analysis (214). As expected, $\mathrm{LBR}^{-/-}$thymocytes presented an inverted nuclear architecture with heterochromatin localized in the nuclear center while euchromatin pushed towards the periphery. However, despite this striking change in subnuclear organization, the authors detected only moderate changes in compartmentalization and TAD organization. This suggests that $\mathrm{NL}$ is critical for the peripheral positioning of heterochromatic regions but not involved in the spatial segregation between heterochromatin and euchromatin (B and A compartments).

Taken together, the abovementioned reports support that during lymphocyte development and activation several dynamic chromatin changes take place at the NL compartment, controlling the expression of immune-related genes. Lymphocyte nuclear periphery is not exclusively linked to gene repression, but can also function as a permissive microenvironment, that can host either accessible chromatin regions and/or active genes that are important for lymphocyte development and adaptive immune responses.

\section{CHAPTER V: ALTERATIONS OF THE 3D CHROMATIN ORGANIZATION UPON LYMPHOID TRANSFORMATION}

Alterations that affect the function or levels of critical TFs and epigenetic modulators are well-appreciated drivers of lymphoid transformation by inducing a global dysregulation of the transcriptional program and epigenetic landscape $(215,216)$. Increasing evidence supports that perturbations of structural proteins involved in $3 \mathrm{D}$ chromatin organization might also play critical roles in lymphoid malignancies (217). The development of advanced imaging and 3C techniques over the past years combined with elegant genetic models allowed for a better understanding of the extent of $3 \mathrm{D}$ chromatin dysregulation during lymphoid malignancies and its potential role in driving transformation (Table $\mathbf{1}$ ).

\section{Lamin Dysregulation}

One of the first nuclear organizers that were discovered to promote lymphoid transformation were Lamin A/C. Downregulation of type A Lamin genes by hypermethylation of Lamin A/C promoters occurs in about $20 \%$ of B-cell Acute 
TABLE 1 | Overview of 3D chromatin alterations in lymphoid malignancies.

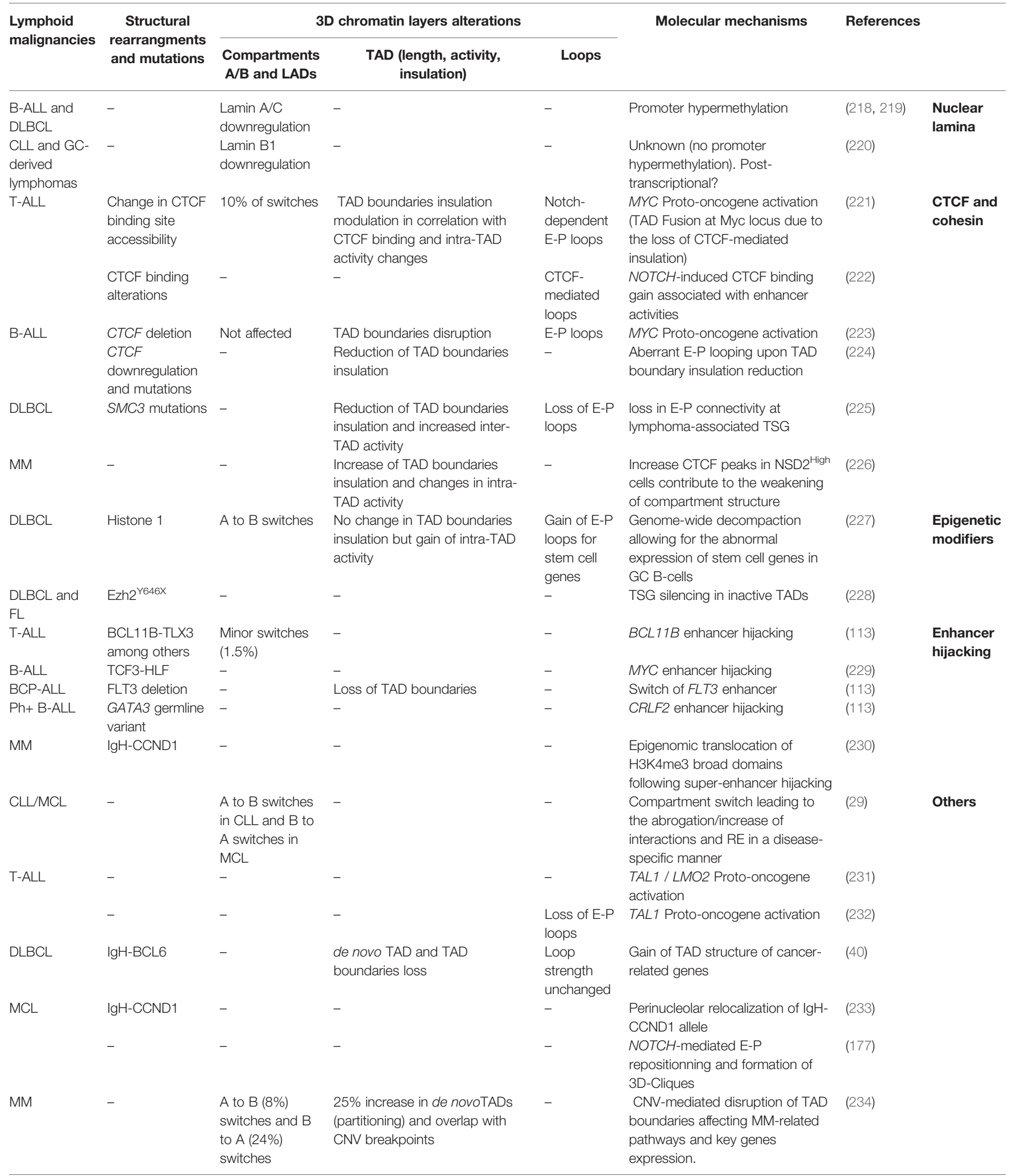

B-ALL, B-cell Acute Lymphoblastic Leukemia; DLBCL, Diffuse Large B-cell Lymphomas; CLL, Chronic Lymphocytic Leukemia; MCL, Mantle Cell Lymphoma; T-ALL, T-cell Acute Lymphoblastic Leukemia; MM, Multiple Myeloma; FL, Follicular Lymphoma; BCP-ALL, B-Cell Precursor Acute Lymphoblastic Leukemia; Ph+ B-ALL, Philadelphia chromosome-positive ALL; TAD, Topologically Associating Domain; CNV, Copy Number Variation; E-P, Enhancer-Promoter; TSG, Tumor Suppressor Gene; RE, Regulatory Element. 
Lymphoblastic Leukemia (B-ALL) and 35\% of Diffuse Large Bcell Lymphomas (DLBCL) patients and are associated to poor prognosis $(218,219)$. Although the loss of A/C lamin was hypothesized to contribute to genomic instability and aneuploidy by preventing proper cytokinesis (235), defects on 3D chromatin organization cannot be excluded. Lamin B1, which maintains the $I g h \mathrm{~V}$ genomic segments within the repressive heterochromatin in naive $\mathrm{B}$ cells, has also been shown to be involved in B-cell malignancies (220). Its transient downregulation has been reported to be necessary for the GC reaction and more particularly for $I g h \mathrm{~V}$ transcription and somatic hypermutation (SHM) upon antigen encounter. In comparison to normal human reactive lymph nodes, Lamin B1 expression has been documented to be further decreased and permanently locked in primary GC derived B-cell lymphoma and in transformed Follicular Lymphoma (FL). Together, these reports support a role for lamins and LADs dysregulation in the initiation and the progression of lymphoid malignancies beyond genomic instability.

\section{Compartment Switches}

A/B-compartment switching has been identified in $\mathrm{T}$ and $\mathrm{B}$ cell malignancies, albeit the functional and biological consequences of these alterations remain to be determined, in a cell-specific and context-dependent manner. A recent study comparing Chronic Lymphocytic Leukemia (CLL) and Mantle Cell Lymphoma (MCL) patient samples to normal B cells reported that about $25 \%$ of the genome undergoes compartmental changes (29). These switches were mostly associated to a global inactivation (A to B) in CLL and activation (B to A) in MCL, suggesting that while similar cellular transformation mechanisms might be in place for these neoplasms supposedly originating from memory and naive $\mathrm{B}$ cells, disease-specific 3D chromatin topology alterations might be uncovered (29). When comparing CLL to naive B cells, the EBF1 locus was associated with a shift from A to I compartment along with a drastic loss of enhancer activity and weakening of E-P interaction, consistent with the low expression of the EBF1 gene as a diagnostic marker in CLL. A similar study comparing T-cell Acute Lymphoblastic Leukemia (T-ALL) genome to normal peripheral T-cells revealed that about $10 \%$ of the genome experienced compartmental changes which were subtype-specific (221).

\section{Changes in TAD Activity and Boundary Insulation}

Common TAD alterations in cancer include TAD fusions or splits due to the loss or de novo establishment of TAD boundaries, respectively (236). These changes have been associated with downregulation of Tumor Suppressor Genes (TSG) or overexpression of oncogenes within TADs. About $10 \%$ of TAD boundaries changed upon T-cell transformation to T-ALL, with more than half of these changes associated with altered CTCF binding (221). At the global level, this study demonstrated a correlation between increased intra-TAD activity and transcriptional upregulation as well as higher boundary insulation enriched with CTCF and Notch binding.
Conversely, weakening of TAD boundaries and downregulation of proximal genes was recently described in hyper-diploid B-ALL patients which usually present lower CTCF expression (224).

Using a low-input $\mathrm{Hi}-\mathrm{C}$ method, Diaz et al. were able to profile chromatin interactions in primary DLBCL cells in comparison to peripheral B cells. This analysis uncovered $>600$ regions with altered interaction patterns and $6 \%$ of these corresponded to de novo patients-specific TADs. Furthermore, some of these neo-TADs were located around cancer related genes such as TP63 or TPRG1 in the vicinity of BCL6 locus (40) although both the driving mechanisms and functional consequences of these reorganization remain to be tested. Similarly, the Hi-C analysis in DLBCL cell lines with gain of function Ezh2 mutation (Ezh2 ${ }^{\mathrm{Y} 646 \mathrm{~F}}$ ) could not identify major topological changes compared to Ezh2 ${ }^{\mathrm{WT}}$ cells but only focal effects on selected TADs (228). Increased deposition of H3K27me3 occurred predominantly around regions that were already decorated by this mark, arguing for a possible spreading mechanism rather than de novo establishment. Along with increased levels of $\mathrm{H} 3 \mathrm{~K} 27 \mathrm{me} 3$, the authors identified transcriptional downregulation of multiple TSG such as FOXO3 and ARMC2 within "inactive" TADs due to loss of promoter interactions (228).

\section{Enhancer-Promoter Rewiring}

$3 \mathrm{D}$ chromatin changes that directly affect E-P communication of tumor suppressor genes or proto-oncogenes have been extensively described in hematological malignancies $(236,237)$. The MYC oncogene is a critical regulator of NOTCH1-mediated T-ALL. A long-range interaction between $M y c$ promoter and its distal ( 1.4 Mb) Notch1-bound enhancer (N-Me) occurs transiently during T-cell development, specifically at DN3 and DN4 stage, to support Notch-Myc driven growth. More than $60 \%$ of T-ALL patients show constitutive activation of the $\mathrm{NOTCH}$ pathway and aberrant upregulation of $\mathrm{Myc}$ expression, partly mediated through the re-establishment of $\mathrm{N}$ $\mathrm{Me} / \mathrm{Myc}$ contact, as confirmed by conditional deletion of $\mathrm{N}-\mathrm{Me}$ in mice (238). Another study in T-ALL, identified a recurrent TAD fusion around the $M y c$ locus along with a major increase in inter-TAD interactions upon the loss of Notch/CTCF-mediated insulation as shown by $4 \mathrm{C}$-seq and functionally validated by $3 \mathrm{D}$ DNA-FISH (221). The role of NOTCH1 in aberrant 3D chromatin reorganization has been also reported in $\mathrm{B}$ cell lymphoma, where NOTCH1 mediates spatial clusters of longrange E-P interactions forming hyperconnected "3D cliques", which include crucial protooncogenes (177).

\section{Mechanisms for 3D Reorganization in Cancer}

Genetic or epigenetic alterations that affect the function or binding of genome organizers is the most common mechanism which induces local or global topological changes during malignant transformation. Heterozygous, loss-of-function mutations of key architectural factors, such as CTCF and various subunits of the cohesin complex, are frequently detected in myeloid (239-241) and lymphoblastic leukemia 
$(242,243)$. Initially it was proposed that cohesinopathies, could be involved in tumorigenesis by the induction of genomic instability (244). While this hypothesis remains plausible, most of blood malignancies demonstrate limited aneuploidy arguing for additional mechanisms.

A recent study, using a conditional knock out (cKO) mouse model showed that haploinsufficiency of the cohesion subunit Smc3 in GC B cells, leads to GC hyperplasia and impairs plasma cell differentiation (225). Hi-C analysis revealed an overall reduction of TAD boundaries insulation resulting in increased inter-TAD associations. More importantly, there was a significant reduction of intra-TAD interactions in Smc3haploinsufficient GCs, which correlated with transcriptional downregulation of implicated genes. The most dramatic loss in connectivity occurred around enhancers and promoters, especially around lymphoma-associated TSG, such Dusp4, Zeb2 and others.

In addition to genetic alterations of architectural factors, epigenetic changes might also affect binding and/or function of these proteins and perturb loop extrusion. Indeed, CTCF binding is sensitive to cytosine methylation within the CTCF-binding elements (CBE) (160). Given that global methylation alterations frequently occur in $\mathrm{T}$ and B-cell malignancies due to TET2, DNMT3A and IDH2 mutations (245-247), it is reasonable to expect changes in CTCF binding and thus, in TAD boundary insulation. Mutations on CBE elements may also affect CTCF binding and local chromatin conformation (162) and could possibly function as cancer drivers (248). Surprisingly, loss of CTCF binding at specific TAD boundaries and CBE in T-ALL is neither associated with somatic mutations nor is accompanied by increased DNA methylation but rather with a localized reduced chromatin accessibility (221). This new paradigm of alteration of looping machinery organizer remains to be further investigated in other immune related diseases and malignancies as well.

Chromosomal rearrangements originating from double strand breaks (DSBs) are frequent in lymphoid malignancies and do not constitute a stochastic process, as intrachromosomal segments are more frequently targeted compared to interchromosomal ones in B cells $(249,250)$. Integration of $\mathrm{Hi}-\mathrm{C}$ profiling and DSB induction by etoposide in B cells demonstrated that TAD boundaries are enriched for CTCF/ cohesin while topoisomerase II complexes are hotspots for genomic rearrangements (251). The chimeric TF TCF3-HLF, which confers treatment resistance in ALL was recently shown to act as a pioneer factor that aberrantly activates a distal $M y c$ enhancer and mediates interaction with the its promoter and therefore its overexpression (229). While this chimeric TF seems to interact with ETS factors to regulate enhancer function, it was also shown to physically form a complex with multiple chromatin organizers such as CTCF and YY1 as well as with the histone acetyltransferase p300 (EP300). Indeed, TCF3-HLF deletion leads to a reduction of EP300 mediated H3K27ac deposition at TCF3HLF binding sites. In agreement, in vivo treatment with JQ1 and A-485 inhibitors caused reduced BRD recruitment on enhancers and downregulation of $M y c$ expression, indicating p300 or BRD proteins as potential therapeutic target for ALL.
Finally, deletions at 13q12.2 in B-Cell Precursor Acute Lymphoblastic Leukemia (BCP-ALL) lead to the loss of TAD boundaries and gain/rewiring of E-P loops sustaining the expression of the common leukemia driver FLT3 (252). Similarly, de novo long-range interactions enabling the expression of the protooncogenes TAL1 and LMO2 (231) have been documented in T-ALL, posing the disruption of insulated neighborhoods as a new paradigm in lymphoid transformation.

\section{Reversibility of Chromatin Alterations and Therapeutic Strategies}

Chromatin conformation techniques have been proposed to serve as novel diagnostic tools by looking at the emergence of translocations, copy number alterations (CNA) and new regulatory loops or subtypes within human B-cell malignancies (253). Theoretically, DNMTi (5-azacytidine and decitabine) treatment for patients presenting a hypermethylated genome along with TET, IDH1/2 or DNMT3A mutations, could have therapeutic potential by restoring CTCF binding to CBE. While this treatment is increasingly used in clinic (254), the effects on CTCF binding and 3D chromatin organization have widely not been investigated. However, a recent study in T-ALL cell lines treated with 5-azacytidine showed no restoration of CTCF binding, challenging this therapeutic opportunity (221).

Clinical trials assessing another inhibitor targeting the catalytic activity of Ezh2 (255), was sufficient to re-activate the expression of multiple tumor suppressor genes (such as FOXO3, SESN1, and ARMC2) and restore the connectivity of the respective TADs in Ezh2 ${ }^{\mathrm{Y} 646 \mathrm{~F}}$ mutated B-cell lymphoma cells, without inducing other changes of the chromatin compartmentalization into TADs (228). Finally, treatment of T-ALL cell lines with NOTCH1 inhibitor $\gamma$-secretase $(\gamma$-SI) led to loss of H3K27ac from select (sensitive) enhancers, without affecting intra-TAD activity nor TAD boundary insulation. However, treatments with the CDK7 inhibitor THZ1 was able to reduce the activity of $M y c$ distal enhancers as well as their interaction with $M y c$ promoter and restore the original TAD structure within the $M y c$ locus, which remain unaltered upon $\gamma \mathrm{SI}$ treatment (221).

\section{DISCUSSION}

Over the last decades, multiples studies have shed light into the principles, mechanisms and biological significance of $3 \mathrm{D}$ chromatin reorganization occurring upon lymphopoiesis. Although these studies offered snapshots of specific stages and transitions, many pieces in the $3 \mathrm{D}$ puzzle of lymphopoiesis are still missing due to technical difficulties to capture and/or characterize transient and dynamic subpopulations.

How is $3 \mathrm{D}$ genomic architecture reorganized throughout lymphopoiesis and upon immune response and how does it associate with transcriptional changes? Application and further improvement of single-cell multi-omics technologies (such as scHi-C (115, 256), HiCAR (257), GAM (258), scRNA/ATAC 
(259) etc.) at high-resolution, will enable the construction of complete $3 \mathrm{D}$ lymphopoietic molecular roadmaps. It will provide a better understanding of the temporal interconnections between 3D organization, chromatin state, transcription and cell fate. This will also enable the precise $3 \mathrm{D}$ chromatin mapping of specific developmental stages that have not been investigated so far (e.g. memory B cells). As recently described for CTCF loss in murine B cells, special attention should be paid to cytokinemediated ex vivo activation, as an alternative to the in vivo characterization and isolation. As shown in B cells, CD40 activation mimics the in vivo CTCF loss sensitivity on the contrary to IL-4/LPS treatment (165).

The recent development of CRISPR-(d)Cas9 (260), Degron (127) and super-resolution live imaging technologies allowed inducible spatiotemporal perturbation of cellular processes (including transcription and cell cycle modulation) and genome organizers function. Using such approaches, will enable to decipher in a more definitive and quantitative manner the extent to which $3 \mathrm{D}$ chromatin organization and transcriptional activity are functionally interconnected during lymphopoiesis. As we discussed above, a large number of 3D organization players have been suggested to mediate E-P loops and to be involved in compartment, hyperconnected TAD or hubs. However, most of the studies provide associations and not direct experimental evidence for the architectural roles of these factors and the underlying mechanisms.

Which factors and processes are critical for building or maintaining 3D chromatin organization at different stages of B/T lymphopoiesis? An answer to this question might be provided through the involvement of the non-coding RNAs, which are increasingly appreciated as chromatin mediators in various systems (261). Given that a large number of non-coding RNAs are expressed in the immune system and specifically during lymphopoiesis $(211,262)$, they could possibly be considered as good candidates controlling local chromatin topology and distal interactions. Hence, further investigations

\section{REFERENCES}

1. Rothenberg EV. Transcriptional Control of Early $\mathrm{T}$ and B Cell Developmental Choices. Annu Rev Immunol (2014) 32:283-321. doi: 10.1146/annurev-immunol-032712-100024

2. Karimi MM, Guo Y, Cui X, Pallikonda HA, Horkova V, Wang YF, et al. The Order and Logic of CD4 Versus CD8 Lineage Choice and Differentiation in Mouse Thymus. Nat Commun (2021) 12(1):99. doi: 10.1038/s41467-02020306-w

3. O'Shea JJ, Paul WE. Mechanisms Underlying Lineage Commitment and Plasticity of Helper CD4+ T Cells. Science (2010) 327(5969):1098-102. doi: $10.1126 /$ science. 1178334

4. Carrelha J, Meng Y, Kettyle LM, Luis TC, Norfo R, Alcolea V, et al. Hierarchically Related Lineage-Restricted Fates of Multipotent Haematopoietic Stem Cells. Nature (2018) 554(7690):106-11. doi: 10.1038 /nature25455

5. Dzierzak E, Bigas A. Blood Development: Hematopoietic Stem Cell Dependence and Independence. Cell Stem Cell (2018) 22(5):639-51. doi: 10.1016/j.stem.2018.04.015

6. von Boehmer H, Melchers F. Checkpoints in Lymphocyte Development and Autoimmune Disease. Nat Immunol (2010) 11(1):14-20. doi: 10.1038/ni.1794 towards this direction should be conducted. Although the phase separation mechanism has only recently been introduced in other cell types, 3D nuclear architecture studies in this direction, during lymphocyte development and activation could shed more lights on understanding the regulatory landscapes and their correlation with gene expression alterations and diseases $(263,264)$. Identifying the mediators and the principles of $3 \mathrm{D}$ chromatin reorganization that ensures proper lymphocyte development and differentiation, is critical to determine their potential alterations in lymphoid malignancies. Targeting specific architectural dysregulations (such as enhancer hijacking, cliques, etc.) that take place upon lymphoid transformations, might in the future open avenues to the development of novel therapeutic strategies.

\section{AUTHOR CONTRIBUTIONS}

LS, ES, and EA conceptualized the manuscript. LS drafted all Bcell relevant parts and the tumorigenesis chapter. ES drafted all T-cell relevant parts. EA supervised, coordinated and wrote the final manuscript. LS and ES contributed equally. EA is the corresponding author. All authors contributed to the article and approved the submitted version.

\section{ACKNOWLEDGMENTS}

We are grateful to Petros Tzerpos, Martin Rivas and the members of the Apostolou lab for critical reading of the manuscript. LS is supported by the Lady TATA Memorial Fund and the Lymphoma Research Foundation. E.A. is supported by the NIGMS (1R01GM138635), NIDDK (1U01DK128852 by 4DN), and the Mark Foundation for Cancer Research and the TriInstitutional Stem Cell Initiative.

7. Basso K, Dalla-Favera R. Germinal Centres and B Cell Lymphomagenesis. Nat Rev Immunol (2015) 15(3):172-84. doi: 10.1038/nri3814

8. Germain RN. T-Cell Development and the CD4-CD8 Lineage Decision. Nat Rev Immunol (2002) 2(5):309-22. doi: 10.1038/nri798

9. Kee BL, Murre C. Transcription Factor Regulation of B Lineage Commitment. Curr Opin Immunol (2001) 13(2):180-5. doi: 10.1016/ S0952-7915(00)00202-8

10. Rothenberg EV. Programming for T-lymphocyte Fates: Modularity and Mechanisms. Genes Dev (2019) 33(17-18):1117-35. doi: 10.1101/gad.327163.119

11. Johanson TM, Chan WF, Keenan CR, Allan RS. Genome Organization in Immune Cells: Unique Challenges. Nat Rev Immunol (2019) 19(7):448-56. doi: 10.1038/s41577-019-0155-2

12. Smale ST, Fisher AG. Chromatin Structure and Gene Regulation in the Immune System. Annu Rev Immunol (2002) 20:427-62. doi: 10.1146/ annurev.immunol.20.100301.064739

13. Fraser P, Bickmore W. Nuclear Organization of the Genome and the Potential for Gene Regulation. Nature (2007) 447(7143):413-7. doi: 10.1038/nature05916

14. Lanctot C, Cheutin T, Cremer M, Cavalli G, Cremer T. Dynamic Genome Architecture in the Nuclear Space: Regulation of Gene Expression in Three Dimensions. Nat Rev Genet (2007) 8(2):104-15. doi: 10.1038/nrg2041 
15. Roix JJ, McQueen PG, Munson PJ, Parada LA, Misteli T. Spatial Proximity of Translocation-Prone Gene Loci in Human Lymphomas. Nat Genet (2003) 34(3):287-91. doi: 10.1038/ng1177

16. Misteli T, Soutoglou E. The Emerging Role of Nuclear Architecture in DNA Repair and Genome Maintenance. Nat Rev Mol Cell Biol (2009) 10(4):24354. doi: $10.1038 / \mathrm{nrm} 2651$

17. Gilbert DM, Takebayashi SI, Ryba T, Lu J, Pope BD, Wilson KA, et al. Space and Time in the Nucleus: Developmental Control of Replication Timing and Chromosome Architecture. Cold Spring Harb Symp Quant Biol (2010) 75:143-53. doi: 10.1101/sqb.2010.75.011

18. Qiu X, Ma F, Zhao M, Cao Y, Shipp L, Liu A, et al. Altered 3D Chromatin Structure Permits Inversional Recombination at the IgH Locus. Sci Adv (2020) 6(33):eaaz8850. doi: 10.1126/sciadv.aaz8850

19. Ubelmesser N, Papantonis A. Technologies to Study Spatial Genome Organization: Beyond 3C. Brief Funct Genomics (2019) 18(6):395-401. doi: 10.1093/bfgp/elz019

20. Barth R, Bystricky K, Shaban HA. Coupling Chromatin Structure and Dynamics by Live Super-Resolution Imaging. Sci Adv (2020) 6(27). doi: 10.1126/sciadv.aaz2196

21. Kempfer R, Pombo A. Methods for Mapping 3D Chromosome Architecture. Nat Rev Genet (2020) 21(4):207-26. doi: 10.1038/s41576-019-0195-2

22. Li Y, Eshein A, Virk RKA, Eid A, Wu W, Frederick J, et al. Nanoscale Chromatin Imaging and Analysis Platform Bridges 4D Chromatin Organization With Molecular Function. Sci Adv (2021) 7(1). doi: 10.1017/ S1431927620016785

23. Cremer T, Cremer M. Chromosome Territories. Cold Spring Harb Perspect Biol (2010) 2(3):a003889. doi: 10.1101/cshperspect.a003889

24. Lieberman-Aiden E, van Berkum NL, Williams L, Imakaev M, Ragoczy T, Telling A, et al. Comprehensive Mapping of Long-Range Interactions Reveals Folding Principles of the Human Genome. Science (2009) 326 (5950):289-93. doi: 10.1126/science.1181369

25. Wang S, Su JH, Beliveau BJ, Bintu B, Moffitt JR, Wu CT, et al. Spatial Organization of Chromatin Domains and Compartments in Single Chromosomes. Science (2016) 353(6299):598-602. doi: 10.1126/ science.aaf8084

26. Guelen L, Pagie L, Brasset E, Meuleman W, Faza MB, Talhout W, et al. Domain Organization of Human Chromosomes Revealed by Mapping of Nuclear Lamina Interactions. Nature (2008) 453(7197):948-51. doi: 10.1038 /nature 06947

27. Peric-Hupkes D, Meuleman W, Pagie L, Bruggeman SW, Solovei I, Brugman W, et al. Molecular Maps of the Reorganization of Genome-Nuclear Lamina Interactions During Differentiation. Mol Cell (2010) 38(4):603-13. doi: 10.1016/j.molcel.2010.03.016

28. Pombo A, Dillon N. Three-Dimensional Genome Architecture: Players and Mechanisms. Nat Rev Mol Cell Biol (2015) 16(4):245-57. doi: 10.1038/ nrm3965

29. Vilarrasa-Blasi R, Soler-Vila P, Verdaguer-Dot N, Russinol N, Di Stefano M, Chapaprieta V, et al. Dynamics of Genome Architecture and Chromatin Function During Human B Cell Differentiation and Neoplastic Transformation. Nat Commun (2021) 12(1):651. doi: 10.1038/s41467-020-20849-y

30. Dixon JR, Selvaraj S, Yue F, Kim A, Li Y, Shen Y, et al. Topological Domains in Mammalian Genomes Identified by Analysis of Chromatin Interactions. Nature (2012) 485(7398):376-80. doi: 10.1038/nature11082

31. Nora EP, Lajoie BR, Schulz EG, Giorgetti L, Okamoto I, Servant N, et al. Spatial Partitioning of the Regulatory Landscape of the X-inactivation Centre. Nature (2012) 485(7398):381-5. doi: 10.1038/nature11049

32. Szabo Q, Bantignies F, Cavalli G. Principles of Genome Folding Into Topologically Associating Domains. Sci Adv (2019) 5(4):eaaw1668. doi: $10.1126 /$ sciadv.aaw1668

33. Anania C, Lupianez DG. Order and Disorder: Abnormal 3D Chromatin Organization in Human Disease. Brief Funct Genomics (2020) 19(2):128-38. doi: 10.1093/bfgp/elz028

34. Holwerda S, de Laat W. Chromatin Loops, Gene Positioning, and Gene Expression. Front Genet (2012) 3:217. doi: 10.3389/fgene.2012.00217

35. Dekker J, Mirny L. The 3D Genome as Moderator of Chromosomal Communication. Cell (2016) 164(6):1110-21. doi: 10.1016/j.cell.2016.02.007

36. Kadauke S, Blobel GA. Chromatin Loops in Gene Regulation. Biochim Biophys Acta (2009) 1789(1):17-25. doi: 10.1016/j.bbagrm.2008.07.002
37. Jin W, Tang Q, Wan M, Cui K, Zhang Y, Ren G, et al. Genome-Wide Detection of Dnase I Hypersensitive Sites in Single Cells and FFPE Tissue Samples. Nature (2015) 528(7580):142-6. doi: 10.1038/nature15740

38. Ren G, Jin W, Cui K, Rodrigez J, Hu G, Zhang Z, et al. Ctcf-Mediated Enhancer-Promoter Interaction Is a Critical Regulator of Cell-to-Cell Variation of Gene Expression. Mol Cell (2017) 67(6):1049-58 e6. doi: 10.1016/j.molcel.2017.08.026

39. Hu G, Cui K, Fang D, Hirose S, Wang X, Wangsa D, et al. Transformation of Accessible Chromatin and 3D Nucleome Underlies Lineage Commitment of Early T Cells. Immunity (2018) 48(2):227-42 e8. doi: 10.1016/j.immuni.2018.01.013

40. Diaz N, Kruse K, Erdmann T, Staiger AM, Ott G, Lenz G, et al. Chromatin Conformation Analysis of Primary Patient Tissue Using a Low Input Hi-C Method. Nat Commun (2018) 9(1):4938. doi: 10.1038/s41467-018-06961-0

41. Zhang C, Xu Z, Yang S, Sun G, Jia L, Zheng Z, et al. Taghi-C Reveals 3d Chromatin Architecture Dynamics During Mouse Hematopoiesis. Cell Rep (2020) 32(13):108206. doi: 10.1016/j.celrep.2020.108206

42. Cremer T, Cremer C, Baumann H, Luedtke EK, Sperling K, Teuber V, et al. Rabl's Model of the Interphase Chromosome Arrangement Tested in Chinese Hamster Cells by Premature Chromosome Condensation and laser-UV-microbeam Experiments. Hum Genet (1982) 60(1):46-56. doi: 10.1007/BF00281263

43. Hsieh TS, Cattoglio C, Slobodyanyuk E, Hansen AS, Rando OJ, Tjian R, et al. Resolving the 3D Landscape of Transcription-Linked Mammalian Chromatin Folding. Mol Cell (2020) 78(3):539-53.e8. doi: 10.1016/ j.molcel.2020.03.002

44. Bonev B, Mendelson Cohen N, Szabo Q, Fritsch L, Papadopoulos GL, Lubling Y, et al. Multiscale 3D Genome Rewiring During Mouse Neural Development. Cell (2017) 171(3):557-72 e24. doi: 10.1016/j.cell.2017.09.043

45. Di Giammartino DC, Kloetgen A, Polyzos A, Liu Y, Kim D, Murphy D, et al. KLF4 is Involved in the Organization and Regulation of PluripotencyAssociated Three-Dimensional Enhancer Networks. Nat Cell Biol (2019) 21(10):1179-90. doi: 10.1038/s41556-019-0390-6

46. Ioannou D, Kandukuri L, Simpson JL, Tempest HG. Chromosome Territory Repositioning Induced by PHA-activation of Lymphocytes: A 2D and 3D Appraisal. Mol Cytogenet (2015) 8:47. doi: 10.1186/s13039-015-0146-3

47. Amrichova J, Lukasova E, Kozubek S, Kozubek M. Nuclear and Territorial Topography of Chromosome Telomeres in Human Lymphocytes. Exp Cell Res (2003) 289(1):11-26. doi: 10.1016/S0014-4827(03)00208-8

48. Kupper K, Kolbl A, Biener D, Dittrich S, von Hase J, Thormeyer T, et al. Radial Chromatin Positioning is Shaped by Local Gene Density, Not by Gene Expression. Chromosoma (2007) 116(3):285-306. doi: 10.1007/s00412007-0098-4

49. Bickmore WA. The Spatial Organization of the Human Genome. Annu Rev Genomics Hum Genet (2013) 14:67-84. doi: 10.1146/annurev-genom091212-153515

50. Tanabe H, Muller S, Neusser M, von Hase J, Calcagno E, Cremer M, et al. Evolutionary Conservation of Chromosome Territory Arrangements in Cell Nuclei From Higher Primates. Proc Natl Acad Sci USA (2002) 99(7):4424-9. doi: 10.1073/pnas.072618599

51. Kim SH, McQueen PG, Lichtman MK, Shevach EM, Parada LA, Misteli T. Spatial Genome Organization During T-cell Differentiation. Cytogenet Genome Res (2004) 105(2-4):292-301. doi: 10.1159/000078201

52. Volpi EV, Chevret E, Jones T, Vatcheva R, Williamson J, Beck S, et al. Large-Scale Chromatin Organization of the Major Histocompatibility Complex and Other Regions of Human Chromosome 6 and its Response to Interferon in Interphase Nuclei. J Cell Sci (2000) 113( Pt 9):1565-76. doi: 10.1242/jcs.113.9.1565

53. Williams RR, Broad S, Sheer D, Ragoussis J. Subchromosomal Positioning of the Epidermal Differentiation Complex (EDC) in Keratinocyte and Lymphoblast Interphase Nuclei. Exp Cell Res (2002) 272(2):163-75. doi: 10.1006/excr.2001.5400

54. Kumar PP, Bischof O, Purbey PK, Notani D, Urlaub H, Dejean A, et al. Functional Interaction Between PML and SATB1 Regulates ChromatinLoop Architecture and Transcription of the MHC Class I Locus. Nat Cell Biol (2007) 9(1):45-56. doi: 10.1038/ncb1516

55. Collins A, Hewitt SL, Chaumeil J, Sellars M, Micsinai M, Allinne J, et al. RUNX Transcription Factor-Mediated Association of Cd4 and Cd8 Enables Coordinate Gene Regulation. Immunity (2011) 34(3):303-14. doi: 10.1016/ j.immuni.2011.03.004 
56. Delaire S, Huang YH, Chan SW, Robey EA. Dynamic Repositioning of CD4 and CD8 Genes During T Cell Development. J Exp Med (2004) 200 (11):1427-35. doi: 10.1084/jem.20041041

57. Brown KE, Guest SS, Smale ST, Hahm K, Merkenschlager M, Fisher AG. Association of Transcriptionally Silent Genes With Ikaros Complexes at Centromeric Heterochromatin. Cell (1997) 91(6):845-54. doi: 10.1016/ S0092-8674(00)80472-9

58. Dekker J, Rippe K, Dekker M, Kleckner N. Capturing Chromosome Conformation. Science (2002) 295(5558):1306-11. doi: 10.1126/science.1067799

59. Shah S, Takei Y, Zhou W, Lubeck E, Yun J, Eng CL, et al. Dynamics and Spatial Genomics of the Nascent Transcriptome by Intron Seqfish. Cell (2018) 174(2):363-76 e16. doi: 10.1016/j.cell.2018.05.035

60. Johanson TM, Lun ATL, Coughlan HD, Tan T, Smyth GK, Nutt SL, et al. Transcription-Factor-Mediated Supervision of Global Genome Architecture Maintains B Cell Identity. Nat Immunol (2018) 19(11):1257-64. doi: 10.1038/s41590-018-0234-8

61. Lin YC, Benner C, Mansson R, Heinz S, Miyazaki K, Miyazaki M, et al. Global Changes in the Nuclear Positioning of Genes and Intra- and Interdomain Genomic Interactions That Orchestrate B Cell Fate. Nat Immunol (2012) 13(12):1196-204. doi: 10.1038/ni.2432

62. Kumari G, Sen R. Chromatin Interactions in the Control of Immunoglobulin Heavy Chain Gene Assembly. Adv Immunol (2015) 128:41-92. doi: 10.1016/ bs.ai.2015.08.001

63. Garrett FE, Emelyanov AV, Sepulveda MA, Flanagan P, Volpi S, Li F, et al. Chromatin Architecture Near a Potential 3' End of the Igh Locus Involves Modular Regulation of Histone Modifications During B-Cell Development and In Vivo Occupancy at CTCF Sites. Mol Cell Biol (2005) 25(4):1511-25. doi: 10.1128/MCB.25.4.1511-1525.2005

64. Bossen C, Mansson R, Murre C. Chromatin Topology and the Regulation of Antigen Receptor Assembly. Annu Rev Immunol (2012) 30:337-56. doi: 10.1146/annurev-immunol-020711-075003

65. Alt FW, Zhang Y, Meng FL, Guo C, Schwer B. Mechanisms of Programmed DNA Lesions and Genomic Instability in the Immune System. Cell (2013) 152(3):417-29. doi: 10.1016/j.cell.2013.01.007

66. Dai HQ, Hu H, Lou J, Ye AY, Ba Z, Zhang X, et al. Loop Extrusion Mediates Physiological Igh Locus Contraction for RAG Scanning. Nature (2021) 590 (7845):338-43. doi: 10.1038/s41586-020-03121-7

67. Jhunjhunwala S, van Zelm MC, Peak MM, Murre C. Chromatin Architecture and the Generation of Antigen Receptor Diversity. Cell (2009) 138(3):435-48. doi: 10.1016/j.cell.2009.07.016

68. Leavy O. V(D)J Recombination: RAG Recombination Centres. Nat Rev Immunol (2010) 10(6):383. doi: 10.1038/nri2789

69. Miyazaki K, Watanabe H, Yoshikawa G, Chen K, Hidaka R, Aitani Y, et al. The Transcription Factor E2A Activates Multiple Enhancers That Drive Rag Expression in Developing T and B Cells. Sci Immunol (2020) 5(51). doi: 10.1126/sciimmunol.abb1455

70. Boya R, Yadavalli AD, Nikhat S, Kurukuti S, Palakodeti D, Pongubala JMR. Developmentally Regulated Higher-Order Chromatin Interactions Orchestrate B Cell Fate Commitment. Nucleic Acids Res (2017) 45 (19):11070-87. doi: 10.1093/nar/gkx722

71. Barajas-Mora EM, Kleiman E, Xu J, Carrico NC, Lu H, Oltz EM, et al. A BCell-Specific Enhancer Orchestrates Nuclear Architecture to Generate a Diverse Antigen Receptor Repertoire. Mol Cell (2019) 73(1):48-60.e5. doi: 10.1016/j.molcel.2018.10.013

72. Spilianakis CG, Lalioti MD, Town T, Lee GR, Flavell RA. Interchromosomal Associations Between Alternatively Expressed Loci. Nature (2005) 435 (7042):637-45. doi: 10.1038/nature03574

73. Crump NT, Ballabio E, Godfrey L, Thorne R, Repapi E, Kerry J, et al. BET Inhibition Disrupts Transcription But Retains Enhancer-Promoter Contact. Nat Commun (2021) 12(1):223. doi: 10.1038/s41467-020-20400-z

74. Muroi S, Naoe Y, Miyamoto C, Akiyama K, Ikawa T, Masuda K, et al. Cascading Suppression of Transcriptional Silencers by ThPOK Seals Helper T Cell Fate. Nat Immunol (2008) 9(10):1113-21. doi: 10.1038/ni.1650

75. Egawa T, Littman DR. ThPOK Acts Late in Specification of the Helper T Cell Lineage and Suppresses Runx-mediated Commitment to the Cytotoxic T Cell Lineage. Nat Immunol (2008) 9(10):1131-9. doi: 10.1038/ni.1652

76. Wang L, Wildt KF, Zhu J, Zhang X, Feigenbaum L, Tessarollo L, et al. Distinct Functions for the Transcription Factors GATA-3 and ThPOK
During Intrathymic Differentiation of CD4(+) T Cells. Nat Immunol (2008) 9(10):1122-30. doi: 10.1038/ni.1647

77. Issuree PD, $\mathrm{Ng} \mathrm{CP}$, Littman DR. Heritable Gene Regulation in the CD4:CD8 T Cell Lineage Choice. Front Immunol (2017) 8:291. doi: 10.3389/ fimmu.2017.00291

78. Taniuchi I, Sunshine MJ, Festenstein R, Littman DR. Evidence for Distinct CD4 Silencer Functions at Different Stages of Thymocyte Differentiation. Mol Cell (2002) 10(5):1083-96. doi: 10.1016/S1097-2765(02)00735-9

79. Jiang H, Peterlin BM. Differential Chromatin Looping Regulates CD4 Expression in Immature Thymocytes. Mol Cell Biol (2008) 28(3):907-12. doi: 10.1128/MCB.00909-07

80. Issuree PD, Day K, Au C, Raviram R, Zappile P, Skok JA, et al. Stage-Specific Epigenetic Regulation of CD4 Expression by Coordinated Enhancer Elements During T Cell Development. Nat Commun (2018) 9(1):3594. doi: 10.1038/s41467-018-05834-w

81. Henson DM, Chou C, Sakurai N, Egawa T. A Silencer-Proximal Intronic Region is Required for Sustained CD4 Expression in Postselection Thymocytes. J Immunol (2014) 192(10):4620-7. doi: 10.4049/jimmunol.1302374

82. Ellmeier W, Sunshine MJ, Losos K, Littman DR. Multiple Developmental Stage-Specific Enhancers Regulate CD8 Expression in Developing Thymocytes and in Thymus-Independent T Cells. Immunity (1998) 9 (4):485-96. doi: 10.1016/S1074-7613(00)80632-9

83. Ktistaki E, Garefalaki A, Williams A, Andrews SR, Bell DM, Foster KE, et al. CD8 Locus Nuclear Dynamics During Thymocyte Development. J Immunol (2010) 184(10):5686-95. doi: 10.4049/jimmunol.1000170

84. Chepelev I, Wei G, Wangsa D, Tang Q, Zhao K. Characterization of Genome-Wide Enhancer-Promoter Interactions Reveals Co-Expression of Interacting Genes and Modes of Higher Order Chromatin Organization. Cell Res (2012) 22(3):490-503. doi: 10.1038/cr.2012.15

85. van Schoonhoven A, Huylebroeck D, Hendriks RW, Stadhouders R. 3D Genome Organization During Lymphocyte Development and Activation. Brief Funct Genomics (2020) 19(2):71-82. doi: 10.1093/bfgp/elz030

86. Rawlings JS, Rosler KM, Harrison DA. The JAK/STAT Signaling Pathway. J Cell Sci (2004) 117(Pt 8):1281-3. doi: 10.1242/jcs.00963

87. Roh TY, Cuddapah S, Cui K, Zhao K. The Genomic Landscape of Histone Modifications in Human T Cells. Proc Natl Acad Sci USA (2006) 103 (43):15782-7. doi: 10.1073/pnas.0607617103

88. Pogo BG, Allfrey VG, Mirsky AE. RNA Synthesis and Histone Acetylation During the Course of Gene Activation in Lymphocytes. Proc Natl Acad Sci USA (1966) 55(4):805-12. doi: 10.1073/pnas.55.4.805

89. Jaehning JA, Stewart CC, Roeder RG. DNA-Dependent RNA Polymerase Levels During the Response of Human Peripheral Lymphocytes to Phytohemagglutinin. Cell (1975) 4(1):51-7. doi: 10.1016/0092-8674(75) 90133-6

90. Drings P, Sonnemann E. Phytohemagglutinin-Induced Increase of Euchromatin Contents in Human Lymphocytes. Res Exp Med (Berl) (1974) 164(1):63-76. doi: 10.1007/BF01851966

91. Kieffer-Kwon KR, Tang Z, Mathe E, Qian J, Sung MH, Li G, et al. Interactome Maps of Mouse Gene Regulatory Domains Reveal Basic Principles of Transcriptional Regulation. Cell (2013) 155(7):1507-20. doi: 10.1016/j.cell.2013.11.039

92. Rawlings JS, Gatzka M, Thomas PG, Ihle JN. Chromatin Condensation Via the Condensin II Complex is Required for Peripheral T-cell Quiescence. EMBO J (2011) 30(2):263-76. doi: 10.1038/emboj.2010.314

93. Salataj E, Stathopoulou C, Hafthornorsson RA, Nikolaou C, Spilianakis CG. Developmental Conservation of microRNA Gene Localization at the Nuclear Periphery. PloS One (2019) 14(11):e0223759. doi: 10.1371/ journal.pone.0223759

94. Spilianakis CG, Flavell RA. Long-Range Intrachromosomal Interactions in the T Helper Type 2 Cytokine Locus. Nat Immunol (2004) 5(10):1017-27. doi: $10.1038 /$ nil115

95. Kieffer-Kwon KR, Nimura K, Rao SSP, Xu J, Jung S, Pekowska A, et al. Myc Regulates Chromatin Decompaction and Nuclear Architecture During B Cell Activation. Mol Cell (2017) 67(4):566-78 e10. doi: 10.1016/ j.molcel.2017.07.013

96. Kulis M, Merkel A, Heath S, Queiros AC, Schuyler RP, Castellano G, et al. Whole-Genome Fingerprint of the DNA Methylome During Human B Cell Differentiation. Nat Genet (2015) 47(7):746-56. doi: 10.1038/ng.3291 
97. Bunting KL, Soong TD, Singh R, Jiang Y, Beguelin W, Poloway DW, et al. Multi-Tiered Reorganization of the Genome During B Cell Affinity Maturation Anchored by a Germinal Center-Specific Locus Control Region. Immunity (2016) 45(3):497-512. doi: 10.1016/j.immuni.2016.08.012

98. Vietri Rudan M, Barrington C, Henderson S, Ernst C, Odom DT, Tanay A, et al. Comparative Hi-C Reveals That CTCF Underlies Evolution of Chromosomal Domain Architecture. Cell Rep (2015) 10(8):1297-309. doi: 10.1016/j.celrep.2015.02.004

99. Chu CS, Hellmuth JC, Singh R, Ying HY, Skrabanek L, Teater MR, et al. Unique Immune Cell Coactivators Specify Locus Control Region Function and Cell Stage. Mol Cell (2020) 80(5):845-61.e10. doi: 10.1016/ j.molcel.2020.10.036

100. Martinez A, Marin VG, Junquera SR, Martinez-Murillo R, Freire M. The Contributions of Santiago Ramon Y Cajal to Cancer Research - 100 Years on. Nat Rev Cancer (2005) 5(11):904-9. doi: 10.1038/nrc1741

101. Bortnick A, He Z, Aubrey M, Chandra V, Denholtz M, Chen K, et al. Plasma Cell Fate Is Orchestrated by Elaborate Changes in Genome Compartmentalization and Inter-chromosomal Hubs. Cell Rep (2020) 31 (1):107470. doi: 10.1016/j.celrep.2020.03.034

102. Chan WF, Coughlan HD, Zhou JHS, Keenan CR, Bediaga NG, Hodgkin PD, et al. Pre-Mitotic Genome Re-Organisation Bookends the B Cell Differentiation Process. Nat Commun (2021) 12(1):1344. doi: 10.1038/s41467-021-21536-2

103. Naumova N, Imakaev M, Fudenberg G, Zhan Y, Lajoie BR, Mirny LA, et al. Organization of the Mitotic Chromosome. Science (2013) 342(6161):948-53. doi: $10.1126 /$ science. 1236083

104. Pelham-Webb B, Murphy D, Apostolou E. Dynamic 3D Chromatin Reorganization During Establishment and Maintenance of Pluripotency. Stem Cell Rep (2020) 15(6):1176-95. doi: 10.1016/j.stemcr.2020.10.012

105. Dalton S. Linking the Cell Cycle to Cell Fate Decisions. Trends Cell Biol (2015) 25(10):592-600. doi: 10.1016/j.tcb.2015.07.007

106. Soufi A, Dalton S. Cycling Through Developmental Decisions: How Cell Cycle Dynamics Control Pluripotency, Differentiation and Reprogramming. Development (2016) 143(23):4301-11. doi: 10.1242/dev.142075

107. Mesin L, Ersching J, Victora GD. Germinal Center B Cell Dynamics. Immunity (2016) 45(3):471-82. doi: 10.1016/j.immuni.2016.09.001

108. Weisel F, Shlomchik M. Memory B Cells of Mice and Humans. Annu Rev Immunol (2017) 35:255-84. doi: 10.1146/annurev-immunol-041015-055531

109. Hewitt SL, High FA, Reiner SL, Fisher AG, Merkenschlager M. Nuclear Repositioning Marks the Selective Exclusion of Lineage-Inappropriate Transcription Factor Loci During T Helper Cell Differentiation. Eur J Immunol (2004) 34(12):3604-13. doi: 10.1002/eji.200425469

110. Grogan JL, Mohrs M, Harmon B, Lacy DA, Sedat JW, Locksley RM. Early Transcription and Silencing of Cytokine Genes Underlie Polarization of T Helper Cell Subsets. Immunity (2001) 14(3):205-15. doi: 10.1016/S10747613(01)00103-0

111. Park JH, Choi Y, Song MJ, Park K, Lee JJ, Kim HP. Dynamic Long-Range Chromatin Interaction Controls Expression of IL-21 in CD4+ T Cells. J Immunol (2016) 196(10):4378-89. doi: 10.4049/jimmunol.1500636

112. Deligianni C, Spilianakis CG. Long-Range Genomic Interactions Epigenetically Regulate the Expression of a Cytokine Receptor. EMBO Rep (2012) 13(9):819-26. doi: 10.1038/embor.2012.112

113. Yang J, McGovern A, Martin P, Duffus K, Ge X, Zarrineh P, et al. Analysis of Chromatin Organization and Gene Expression in T Cells Identifies Functional Genes for Rheumatoid Arthritis. Nat Commun (2020) 11 (1):4402. doi: 10.1038/s41467-020-18180-7

114. Bediaga NG, Coughlan HD, Johanson TM, Garnham AL, Naselli G, Schroder J, et al. Multi-Level Remodelling of Chromatin Underlying Activation of Human T Cells. Sci Rep (2021) 11(1):528. doi: 10.1038/s41598-020-80165-9

115. Nagano T, Lubling Y, Stevens TJ, Schoenfelder S, Yaffe E, Dean W, et al. Single-Cell Hi-C Reveals Cell-to-Cell Variability in Chromosome Structure. Nature (2013) 502(7469):59-64. doi: 10.1038/nature12593

116. Lai B, Tang Q, Jin W, Hu G, Wangsa D, Cui K, et al. Trac-Looping Measures Genome Structure and Chromatin Accessibility. Nat Methods (2018) 15 (9):741-7. doi: 10.1038/s41592-018-0107-y

117. Burren OS, Rubio Garcia A, Javierre BM, Rainbow DB, Cairns J, Cooper NJ, et al. Chromosome Contacts in Activated T Cells Identify Autoimmune Disease Candidate Genes. Genome Biol (2017) 18(1):165. doi: 10.1186/ s13059-017-1285-0
118. Javierre BM, Burren OS, Wilder SP, Kreuzhuber R, Hill SM, Sewitz S, et al. Lineage-Specific Genome Architecture Links Enhancers and Non-coding Disease Variants to Target Gene Promoters. Cell (2016) 167(5):1369-84 e19. doi: 10.1016/j.cell.2016.09.037

119. Mumbach MR, Satpathy AT, Boyle EA, Dai C, Gowen BG, Cho SW, et al. Enhancer Connectome in Primary Human Cells Identifies Target Genes of DiseaseAssociated DNA Elements. Nat Genet (2017) 49(11):1602-12. doi: 10.1038/ng.3963

120. Di Giammartino DC, Polyzos A, Apostolou E. Transcription Factors: Building Hubs in the 3D Space. Cell Cycle (2020) 19(19):2395-410. doi: $10.1080 / 15384101.2020 .1805238$

121. Nuebler J, Fudenberg G, Imakaev M, Abdennur N, Mirny LA. Chromatin Organization by an Interplay of Loop Extrusion and Compartmental Segregation. Proc Natl Acad Sci USA (2018) 115(29):E6697-706. doi: 10.1073/pnas.1717730115

122. Beagan JA, Phillips-Cremins JE. On the Existence and Functionality of Topologically Associating Domains. Nat Genet (2020) 52(1):8-16. doi: 10.1038/s41588-019-0561-1

123. Rada-Iglesias A, Grosveld FG, Papantonis A. Forces Driving the ThreeDimensional Folding of Eukaryotic Genomes. Mol Syst Biol (2018) 14(6): e8214. doi: 10.15252/msb.20188214

124. Rowley MJ, Nichols MH, Lyu X, Ando-Kuri M, Rivera ISM, Hermetz K, et al. Evolutionarily Conserved Principles Predict 3d Chromatin Organization. Mol Cell (2017) 67(5):837-52 e7. doi: 10.1016/j.molcel.2017.07.022

125. Sanborn AL, Rao SS, Huang SC, Durand NC, Huntley MH, Jewett AI, et al. Chromatin Extrusion Explains Key Features of Loop and Domain Formation in Wild-Type and Engineered Genomes. Proc Natl Acad Sci USA (2015) 112 (47):E6456-65. doi: 10.1073/pnas.1518552112

126. Haarhuis JHI, van der Weide RH, Blomen VA, Yanez-Cuna JO, Amendola M, van Ruiten MS, et al. The Cohesin Release Factor Wapl Restricts Chromatin Loop Extension. Cell (2017) 169(4):693-707 e14. doi: 10.1016/j.cell.2017.04.013

127. Nora EP, Goloborodko A, Valton AL, Gibcus JH, Uebersohn A, Abdennur $\mathrm{N}$, et al. Targeted Degradation of CTCF Decouples Local Insulation of Chromosome Domains From Genomic Compartmentalization. Cell (2017) 169(5):930-44 e22. doi: 10.1016/j.cell.2017.05.004

128. Rao SSP, Huang SC, Glenn St Hilaire B, Engreitz JM, Perez EM, KiefferKwon KR, et al. Cohesin Loss Eliminates All Loop Domains. Cell (2017) 171 (2):305-20 e24. doi: 10.1016/j.cell.2017.09.026

129. Schwarzer W, Abdennur N, Goloborodko A, Pekowska A, Fudenberg G, LoeMie Y, et al. Two Independent Modes of Chromatin Organization Revealed by Cohesin Removal. Nature (2017) 551(7678):51-6. doi: 10.1038/nature24281

130. Wutz G, Varnai C, Nagasaka K, Cisneros DA, Stocsits RR, Tang W, et al. Topologically Associating Domains and Chromatin Loops Depend on Cohesin and are Regulated by CTCF, WAPL, and PDS5 Proteins. EMBO J (2017) 36(24):3573-99. doi: 10.15252/embj.201798004

131. Palikyras S, Papantonis A. Modes of Phase Separation Affecting Chromatin Regulation. Open Biol (2019) 9(10):190167. doi: 10.1098/rsob.190167

132. Feric M, Misteli T. Phase Separation in Genome Organization Across Evolution. Trends Cell Biol (2021). doi: 10.1016/j.tcb.2021.03.001

133. Mir M, Bickmore W, Furlong EEM, Narlikar G. Chromatin Topology, Condensates and Gene Regulation: Shifting Paradigms or Just a Phase? Development (2019) 146(19). doi: 10.1242/dev.182766

134. Sabari BR, Dall'Agnese A, Boija A, Klein IA, Coffey EL, Shrinivas K, et al. Coactivator Condensation at Super-Enhancers Links Phase Separation and Gene Control. Science (2018) 361(6400). doi: 10.1126/science.aar3958

135. Chong S, Dugast-Darzacq C, Liu Z, Dong P, Dailey GM, Cattoglio C, et al. Imaging Dynamic and Selective Low-Complexity Domain Interactions That Control Gene Transcription. Science (2018) 361(6400). doi: 10.1126/science.aar2555

136. Boija A, Klein IA, Sabari BR, Dall'Agnese A, Coffey EL, Zamudio AV, et al. Transcription Factors Activate Genes Through the Phase-Separation Capacity of Their Activation Domains. Cell (2018) 175(7):1842-55 el6. doi: 10.1016/j.cell.2018.10.042

137. Tatavosian R, Kent S, Brown K, Yao T, Duc HN, Huynh TN, et al. Nuclear Condensates of the Polycomb Protein Chromobox 2 (CBX2) Assemble Through Phase Separation. J Biol Chem (2019) 294(5):1451-63. doi: 10.1074/jbc.RA118.006620

138. Cho WK, Spille JH, Hecht M, Lee C, Li C, Grube V, et al. Mediator and RNA Polymerase II Clusters Associate in Transcription-Dependent Condensates. Science (2018) 361(6400):412-5. doi: 10.1126/science.aar4199 
139. Zamudio AV, Dall'Agnese A, Henninger JE, Manteiga JC, Afeyan LK, Hannett NM, et al. Mediator Condensates Localize Signaling Factors to Key Cell Identity Genes. Mol Cell (2019) 76(5):753-66.e6. doi: 10.1016/ j.molcel.2019.08.016

140. Kim S, Shendure J. Mechanisms of Interplay Between Transcription Factors and the 3D Genome. Mol Cell (2019) 76(2):306-19. doi: 10.1016/ j.molcel.2019.08.010

141. Weintraub AS, Li CH, Zamudio AV, Sigova AA, Hannett NM, Day DS, et al. Yy1 Is a Structural Regulator of Enhancer-Promoter Loops. Cell (2017) 171 (7):1573-88.e28. doi: 10.1016/j.cell.2017.11.008

142. Grubert F, Srivas R, Spacek DV, Kasowski M, Ruiz-Velasco M, SinnottArmstrong N, et al. Landscape of Cohesin-Mediated Chromatin Loops in the Human Genome. Nature (2020) 583(7818):737-43. doi: 10.1038/s41586020-2151-x

143. Kraft K, Yost KE, Murphy S, Magg A, Long Y, Corces MR, et al. PolycombMediated Genome Architecture Enables Long-Range Spreading of H3K27 Methylation. BioRXiv (2020). doi: 10.1101/2020.07.27.223438

144. Rogers CH, Mielczarek O, Corcoran AE. Dynamic 3D Locus Organization and Its Drivers Underpin Immunoglobulin Recombination. Front Immunol (2020) 11:633705. doi: 10.3389/fimmu.2020.633705

145. Vahedi G. Remodeling the Chromatin Landscape in T Lymphocytes by a Division of Labor Among Transcription Factors. Immunol Rev (2021) 300 (1):167-80. doi: 10.1111/imr.12942

146. Azagra A, Marina-Zarate E, Ramiro AR, Javierre BM, Parra M. From Loops to Looks: Transcription Factors and Chromatin Organization Shaping Terminal B Cell Differentiation. Trends Immunol (2020) 41(1):46-60. doi: 10.1016/j.it.2019.11.006

147. Guo C, Yoon HS, Franklin A, Jain S, Ebert A, Cheng HL, et al. CTCF-Binding Elements Mediate Control of V(D)J Recombination. Nature (2011) 477 (7365):424-30. doi: 10.1038/nature10495

148. Pham D, Moseley CE, Gao M, Savic D, Winstead CJ, Sun M, et al. Batf Pioneers the Reorganization of Chromatin in Developing Effector T Cells Via Ets1-Dependent Recruitment of Ctcf. Cell Rep (2019) 29(5):1203-20.e7. doi: 10.1016/j.celrep.2019.09.064

149. Cuddapah S, Jothi R, Schones DE, Roh TY, Cui K, Zhao K. Global Analysis of the Insulator Binding Protein CTCF in Chromatin Barrier Regions Reveals Demarcation of Active and Repressive Domains. Genome Res (2009) 19 (1):24-32. doi: 10.1101/gr.082800.108

150. Majumder P, Gomez JA, Chadwick BP, Boss JM. The Insulator Factor CTCF Controls MHC Class II Gene Expression and is Required for the Formation of Long-Distance Chromatin Interactions. J Exp Med (2008) 205(4):785-98. doi: 10.1084/jem.20071843

151. Majumder P, Boss JM. Cohesin Regulates MHC Class II Genes Through Interactions With MHC Class II Insulators. J Immunol (2011) 187(8):423644. doi: 10.4049/jimmunol.1100688

152. Hadjur S, Williams LM, Ryan NK, Cobb BS, Sexton T, Fraser P, et al. Cohesins Form Chromosomal Cis-Interactions at the Developmentally Regulated IFNG Locus. Nature (2009) 460(7253):410-3. doi: 10.1038/ nature 08079

153. Schatz DG, Ji Y. Recombination Centres and the Orchestration of V(D)J Recombination. Nat Rev Immunol (2011) 11(4):251-63. doi: 10.1038/ nri2941

154. Jhunjhunwala S, van Zelm MC, Peak MM, Cutchin S, Riblet R, van Dongen JJ, et al. The 3D Structure of the Immunoglobulin Heavy-Chain Locus: Implications for Long-Range Genomic Interactions. Cell (2008) 133(2):26579. doi: $10.1016 /$ j.cell.2008.03.024

155. Zhang Y, Zhang X, Ba Z, Liang Z, Dring EW, Hu H, et al. The Fundamental Role of Chromatin Loop Extrusion in Physiological V(D)J Recombination. Nature (2019) 573(7775):600-4. doi: 10.1038/s41586-019-1547-y

156. Ba Z, Lou J, Ye AY, Dai HQ, Dring EW, Lin SG, et al. CTCF Orchestrates Long-Range Cohesin-Driven V(D)J Recombinational Scanning. Nature (2020) 586(7828):305-10. doi: 10.1038/s41586-020-2578-0

157. Proudhon C, Hao B, Raviram R, Chaumeil J, Skok JA. Long-Range Regulation of V(D)J Recombination. Adv Immunol (2015) 128:123-82. doi: 10.1016/bs.ai.2015.07.003

158. Peters JM. How DNA Loop Extrusion Mediated by Cohesin Enables V(D)J Recombination. Curr Opin Cell Biol (2021) 70:75-83. doi: 10.1016/ j.ceb.2020.11.007
159. Jain S, Ba Z, Zhang Y, Dai HQ, Alt FW. Ctcf-Binding Elements Mediate Accessibility of RAG Substrates During Chromatin Scanning. Cell (2018) 174 (1):102-16.e14. doi: 10.1016/j.cell.2018.04.035

160. Tang Z, Luo OJ, Li X, Zheng M, Zhu JJ, Szalaj P, et al. Ctcf-Mediated Human 3d Genome Architecture Reveals Chromatin Topology for Transcription. Cell (2015) 163(7):1611-27. doi: 10.1016/j.cell.2015.11.024

161. Ribeiro de Almeida C, Hendriks RW, Stadhouders R. Dynamic Control of Long-Range Genomic Interactions at the Immunoglobulin Kappa Light-Chain Locus. Adv Immunol (2015) 128:183-271. doi: 10.1016/bs.ai.2015.07.004

162. Guo C, Gerasimova T, Hao H, Ivanova I, Chakraborty T, Selimyan R, et al. Two Forms of Loops Generate the Chromatin Conformation of the Immunoglobulin Heavy-Chain Gene Locus. Cell (2011) 147(2):332-43. doi: 10.1016/j.cell.2011.08.049

163. Shih HY, Verma-Gaur J, Torkamani A, Feeney AJ, Galjart N, Krangel MS. Tcra Gene Recombination is Supported by a Tcra Enhancer- and CTCFdependent Chromatin Hub. Proc Natl Acad Sci USA (2012) 109(50):E3493502. doi: 10.1073/pnas.1214131109

164. Zhao H, Li Z, Zhu Y, Bian S, Zhang Y, Qin L, et al. A Role of the CTCF Binding Site at Enhancer Ealpha in the Dynamic Chromatin Organization of the Tcra-Tcrd Locus. Nucleic Acids Res (2020) 48(17):9621-36. doi: 10.1093/ nar/gkaa711

165. Perez-Garcia A, Marina-Zarate E, Alvarez-Prado AF, Ligos JM, Galjart N, Ramiro AR. CTCF Orchestrates the Germinal Centre Transcriptional Program and Prevents Premature Plasma Cell Differentiation. Nat Commun (2017) 8:16067. doi: 10.1038/ncomms16067

166. Ribeiro de Almeida C, Heath H, Krpic S, Dingjan GM, van Hamburg JP, Bergen I, et al. Critical Role for the Transcription Regulator CCCTC-binding Factor in the Control of Th2 Cytokine Expression. J Immunol (2009) 182 (2):999-1010. doi: 10.4049/jimmunol.182.2.999

167. Ing-Simmons E, Seitan VC, Faure AJ, Flicek P, Carroll T, Dekker J, et al. Spatial Enhancer Clustering and Regulation of Enhancer-Proximal Genes by Cohesin. Genome Res (2015) 25(4):504-13. doi: 10.1101/gr.184986.114

168. Thiecke MJ, Wutz G, Muhar M, Tang W, Bevan S, Malysheva V, et al. Cohesin-Dependent and -Independent Mechanisms Mediate Chromosomal Contacts Between Promoters and Enhancers. Cell Rep (2020) 32(3):107929. doi: 10.1016/j.celrep.2020.107929

169. Cuartero S, Weiss FD, Dharmalingam G, Guo Y, Ing-Simmons E, Masella S, et al. Control of Inducible Gene Expression Links Cohesin to Hematopoietic Progenitor Self-Renewal and Differentiation. Nat Immunol (2018) 19 (9):932-41. doi: 10.1038/s41590-018-0184-1

170. El Khattabi L, Zhao H, Kalchschmidt J, Young N, Jung S, Van Blerkom P, et al. A Pliable Mediator Acts as a Functional Rather Than an Architectural Bridge Between Promoters and Enhancers. Cell (2019) 178(5):1145-58.e20. doi: 10.1016/j.cell.2019.07.011

171. Boller S, Ramamoorthy S, Akbas D, Nechanitzky R, Burger L, Murr R, et al. Pioneering Activity of the C-Terminal Domain of EBF1 Shapes the Chromatin Landscape for B Cell Programming. Immunity (2016) 44 (3):527-41. doi: 10.1016/j.immuni.2016.02.021

172. Li R, Cauchy P, Ramamoorthy S, Boller S, Chavez L, Grosschedl R. Dynamic EBF1 Occupancy Directs Sequential Epigenetic and Transcriptional Events in B-cell Programming. Genes Dev (2018) 32(2):96-111. doi: 10.1101/ gad.309583.117

173. Johnson JL, Georgakilas G, Petrovic J, Kurachi M, Cai S, Harly C, et al. Lineage-Determining Transcription Factor TCF-1 Initiates the Epigenetic Identity of T Cells. Immunity (2018) 48(2):243-57.e10. doi: 10.1016/ j.immuni.2018.01.012

174. Stadhouders R, Vidal E, Serra F, Di Stefano B, Le Dily F, Quilez J, et al. Transcription Factors Orchestrate Dynamic Interplay Between Genome Topology and Gene Regulation During Cell Reprogramming. Nat Genet (2018) 50(2):238-49. doi: 10.1038/s41588-017-0030-7

175. Dall'Agnese A, Caputo L, Nicoletti C, di Iulio J, Schmitt A, Gatto S, et al. Transcription Factor-Directed Re-Wiring of Chromatin Architecture for Somatic Cell Nuclear Reprogramming Toward Trans-Differentiation. Mol Cell (2019) 76(3):453-72 e8. doi: 10.1016/j.molcel.2019.07.036

176. Magli A, Baik J, Pota P, Cordero CO, Kwak IY, Garry DJ, et al. Pax3 Cooperates With Ldb1 to Direct Local Chromosome Architecture During Myogenic Lineage Specification. Nat Commun (2019) 10(1):2316. doi: 10.1038/s41467-019-10318-6 
177. Petrovic J, Zhou Y, Fasolino M, Goldman N, Schwartz GW, Mumbach MR, et al. Oncogenic Notch Promotes Long-Range Regulatory Interactions Within Hyperconnected 3d Cliques. Mol Cell (2019) 73(6):1174-90.e12. doi: 10.1016/j.molcel.2019.01.006

178. Wei Z, Gao F, Kim S, Yang H, Lyu J, An W, et al. Klf4 Organizes Long-Range Chromosomal Interactions With the Oct4 Locus in Reprogramming and Pluripotency. Cell Stem Cell (2013) 13(1):36-47. doi: 10.1016/ j.stem.2013.05.010

179. Galande S, Purbey PK, Notani D, Kumar PP. The Third Dimension of Gene Regulation: Organization of Dynamic Chromatin Loopscape by SATB1. Curr Opin Genet Dev (2007) 17(5):408-14. doi: 10.1016/j.gde.2007.08.003

180. Stadhouders R, Filion GJ, Graf T. Transcription Factors and 3D Genome Conformation in Cell-Fate Decisions. Nature (2019) 569(7756):345-54. doi: 10.1038/s41586-019-1182-7

181. Yui MA, Rothenberg EV. Developmental Gene Networks: A Triathlon on the Course to T Cell Identity. Nat Rev Immunol (2014) 14(8):529-45. doi: 10.1038/nri3702

182. Hosokawa H, Rothenberg EV. Cytokines, Transcription Factors, and the Initiation of T-Cell Development. Cold Spring Harb Perspect Biol (2018) 10 (5). doi: 10.1101/cshperspect.a028621

183. Hosokawa H, Rothenberg EV. How Transcription Factors Drive Choice of the T Cell Fate. Nat Rev Immunol (2021) 21(3):162-76. doi: 10.1038/s41577020-00426-6

184. Cai S, Lee CC, Kohwi-Shigematsu T. SATB1 Packages Densely Looped, Transcriptionally Active Chromatin for Coordinated Expression of Cytokine Genes. Nat Genet (2006) 38(11):1278-88. doi: 10.1038/ng1913

185. de Belle I, Cai S, Kohwi-Shigematsu T. The Genomic Sequences Bound to Special AT-rich Sequence-Binding Protein 1 (SATB1) In Vivo in Jurkat T Cells are Tightly Associated With the Nuclear Matrix at the Bases of the Chromatin Loops. J Cell Biol (1998) 141(2):335-48. doi: 10.1083/jcb.141.2.335

186. Cai S, Han HJ, Kohwi-Shigematsu T. Tissue-Specific Nuclear Architecture and Gene Expression Regulated by SATB1. Nat Genet (2003) 34(1):42-51. doi: $10.1038 / n g 1146$

187. Kakugawa K, Kojo S, Tanaka H, Seo W, Endo TA, Kitagawa Y, et al. Essential Roles of SATB1 in Specifying T Lymphocyte Subsets. Cell Rep (2017) 19 (6):1176-88. doi: 10.1016/j.celrep.2017.04.038

188. Hao B, Naik AK, Watanabe A, Tanaka H, Chen L, Richards HW, et al. An Anti-Silencer- and SATB1-dependent Chromatin Hub Regulates Rag1 and Rag2 Gene Expression During Thymocyte Development. J Exp Med (2015) 212(5):809-24. doi: 10.1084/jem.20142207

189. Wakabayashi Y, Watanabe H, Inoue J, Takeda N, Sakata J, Mishima Y, et al. Bcl11b is Required for Differentiation and Survival of Alphabeta $\mathrm{T}$ Lymphocytes. Nat Immunol (2003) 4(6):533-9. doi: 10.1038/ni927

190. Li L, Leid M, Rothenberg EV. An Early T Cell Lineage Commitment Checkpoint Dependent on the Transcription Factor Bcl11b. Science (2010) 329(5987):89-93. doi: 10.1126/science.1188989

191. Yu Y, Wang C, Clare S, Wang J, Lee SC, Brandt C, et al. The Transcription Factor Bcl11b is Specifically Expressed in Group 2 Innate Lymphoid Cells and is Essential for Their Development. J Exp Med (2015) 212(6):865-74. doi: $10.1084 /$ jem.20142318

192. Lorentsen KJ, Cho JJ, Luo X, Zuniga AN, Urban JFJr., Zhou L, et al. Bcl11b is Essential for Licensing Th2 Differentiation During Helminth Infection and Allergic Asthma. Nat Commun (2018) 9(1):1679. doi: 10.1038/s41467-01805360-9

193. Sarvagalla S, Kolapalli SP, Vallabhapurapu S. The Two Sides of YY1 in Cancer: A Friend and a Foe. Front Oncol (2019) 9:1230. doi: 10.3389/ fonc.2019.01230

194. Kleiman E, Jia H, Loguercio S, Su AI, Feeney AJ. YY1 Plays an Essential Role at All Stages of B-cell Differentiation. Proc Natl Acad Sci USA (2016) 113(27): E3911-20. doi: 10.1073/pnas.1606297113

195. Mehra P, Gerasimova T, Basu A, Jha V, Banerjee A, Sindhava V, et al. YY1 Controls Emu-3'RR DNA Loop Formation and Immunoglobulin Heavy Chain Class Switch Recombination. Blood Adv (2016) 1(1):15-20. doi: 10.1182/bloodadvances. 2016000372

196. Hwang SS, Kim YU, Lee S, Jang SW, Kim MK, Koh BH, et al. Transcription Factor YY1 is Essential for Regulation of the Th2 Cytokine Locus and for Th2 Cell Differentiation. Proc Natl Acad Sci USA (2013) 110(1):276-81. doi: $10.1073 /$ pnas. 1214682110
197. Cobaleda C, Schebesta A, Delogu A, Busslinger M. Pax5: The Guardian of B Cell Identity and Function. Nat Immunol (2007) 8(5):463-70. doi: 10.1038/ nil454

198. Fuxa M, Skok J, Souabni A, Salvagiotto G, Roldan E, Busslinger M. Pax5 Induces V-to-DJ Rearrangements and Locus Contraction of the Immunoglobulin Heavy-Chain Gene. Genes Dev (2004) 18(4):411-22. doi: 10.1101/gad.291504

199. Rowley MJ, Corces VG. Organizational Principles of 3D Genome Architecture. Nat Rev Genet (2018) 19(12):789-800. doi: 10.1038/s41576018-0060-8

200. Huang J, Marco E, Pinello L, Yuan GC. Predicting Chromatin Organization Using Histone Marks. Genome Biol (2015) 16:162. doi: 10.1186/s13059-015-0740-z

201. Willcockson MA, Healton SE, Weiss CN, Bartholdy BA, Botbol Y, Mishra LN, et al. H1 Histones Control the Epigenetic Landscape by Local Chromatin Compaction. Nature (2021) 589(7841):293-8. doi: 10.1038/s41586-0203032-z

202. Yusufova N, Kloetgen A, Teater M, Osunsade A, Camarillo JM, Chin CR, et al. Histone H1 Loss Drives Lymphoma by Disrupting 3D Chromatin Architecture. Nature (2021) 589(7841):299-305. doi: 10.1038/s41586-0203017-y

203. Prendergast L, Reinberg D. The Missing Linker: Emerging Trends for H1 Variant-Specific Functions. Genes Dev (2021) 35(1-2):40-58. doi: 10.1101/ gad. 344531.120

204. Fyodorov DV, Zhou BR, Skoultchi AI, Bai Y. Emerging Roles of Linker Histones in Regulating Chromatin Structure and Function. Nat Rev Mol Cell Biol (2018) 19(3):192-206. doi: 10.1038/nrm.2017.94

205. Briand N, Collas P. Lamina-Associated Domains: Peripheral Matters and Internal Affairs. Genome Biol (2020) 21(1):85. doi: 10.1186/s13059-02002003-5

206. Hirschhorn R, Decsy MI, Troll W. The Effect of PHA Stimulation of Human Peripheral Blood Lymphocytes Upon Cellular Content of Euchromatin and Heterochromatin. Cell Immunol (1971) 2(6):696-701. doi: 10.1016/00088749(71)90016-5

207. Manteifel VM, Andreichuk TN, Karu TI. A Comparative Study of Chromatin From Lymphocyte Nuclei Upon Activation of Transcription by Irradiation From an He-Ne-laser or Phytohemagglutinin. Mol Biol (Mosk) (1992) 26(5):1054-62.

208. Pompidou A, Rousset S, Mace B, Michel P, Esnous D, Renard N. Chromatin Structure and Nucleic Acid Synthesis in Human Lymphocyte Activation by Phytohemagglutinin. Exp Cell Res (1984) 150(1):213-25. doi: 10.1016/00144827(84)90716-X

209. Kosak ST, Skok JA, Medina KL, Riblet R, Le Beau MM, Fisher AG, et al. Subnuclear Compartmentalization of Immunoglobulin Loci During Lymphocyte Development. Science (2002) 296(5565):158-62. doi: 10.1126/ science. 1068768

210. Robson MI, de Las Heras JI, Czapiewski R, Sivakumar A, Kerr ARW, Schirmer EC. Constrained Release of Lamina-Associated Enhancers and Genes From the Nuclear Envelope During T-cell Activation Facilitates Their Association in Chromosome Compartments. Genome Res (2017) 27 (7):1126-38. doi: 10.1101/gr.212308.116

211. Isoda T, Moore AJ, He Z, Chandra V, Aida M, Denholtz M, et al. NonCoding Transcription Instructs Chromatin Folding and Compartmentalization to Dictate Enhancer-Promoter Communication and T Cell Fate. Cell (2017) 171(1):103-19.e18. doi: 10.1016/j.cell.2017.09.001

212. Park SK, Xiang Y, Feng X, Garrard WT. Pronounced Cohabitation of Active Immunoglobulin Genes From Three Different Chromosomes in Transcription Factories During Maximal Antibody Synthesis. Genes Dev (2014) 28(11):1159-64. doi: 10.1101/gad.237479.114

213. Blobel G. Three-Dimensional Organization of Chromatids by Nuclear Envelope-Associated Structures. Cold Spring Harb Symp Quant Biol (2010) 75:545-54. doi: 10.1101/sqb.2010.75.004

214. Falk M, Feodorova Y, Naumova N, Imakaev M, Lajoie BR, Leonhardt H, et al. Heterochromatin Drives Compartmentalization of Inverted and Conventional Nuclei. Nature (2019) 570(7761):395-9. doi: 10.1038/ s41586-019-1275-3

215. Mlynarczyk C, Fontan L, Melnick A. Germinal Center-Derived Lymphomas: The Darkest Side of Humoral Immunity. Immunol Rev (2019) 288(1):21439. doi: $10.1111 / \mathrm{imr} .12755$ 
216. Sermer D, Pasqualucci L, Wendel HG, Melnick A, Younes A. Emerging Epigenetic-Modulating Therapies in Lymphoma. Nat Rev Clin Oncol (2019) 16(8):494-507. doi: 10.1038/s41571-019-0190-8

217. Ntziachristos P, Abdel-Wahab O, Aifantis I. Emerging Concepts of Epigenetic Dysregulation in Hematological Malignancies. Nat Immunol (2016) 17(9):1016-24. doi: 10.1038/ni.3517

218. Stadelmann B, Khandjian E, Hirt A, Luthy A, Weil R, Wagner HP. Repression of Nuclear Lamin A and C Gene Expression in Human Acute Lymphoblastic Leukemia and non-Hodgkin's Lymphoma Cells. Leuk Res (1990) 14(9):815-21. doi: 10.1016/0145-2126(90)90076-L

219. Agrelo R, Setien F, Espada J, Artiga MJ, Rodriguez M, Perez-Rosado A, et al. Inactivation of the Lamin A/C Gene by CpG Island Promoter Hypermethylation in Hematologic Malignancies, and its Association With Poor Survival in Nodal Diffuse Large B-cell Lymphoma. J Clin Oncol (2005) 23(17):3940-7. doi: 10.1200/ JCO.2005.11.650

220. Klymenko T, Bloehdorn J, Bahlo J, Robrecht S, Akylzhanova G, Cox K, et al. Lamin B1 Regulates Somatic Mutations and Progression of B-cell Malignancies. Leukemia (2018) 32(2):364-75. doi: 10.1038/leu.2017.255

221. Kloetgen A, Thandapani P, Ntziachristos $P$, Ghebrechristos $Y$, Nomikou S, Lazaris C, et al. Three-Dimensional Chromatin Landscapes in T Cell Acute Lymphoblastic Leukemia. Nat Genet (2020) 52(4):388-400. doi: 10.1038/s41588-020-0602-9

222. Fang C, Wang Z, Han C, Safgren SL, Helmin KA, Adelman ER, et al. CancerSpecific CTCF Binding Facilitates Oncogenic Transcriptional Dysregulation. Genome Biol. (2020) 21(1):247.

223. Hyle J, Zhang Y, Wright S, Xu B, Shao Y, Easton J, et al. Acute Depletion of CTCF Directly Affects MYC Regulation Through Loss of EnhancerPromoter Looping. Nucleic Acids Res (2019) 47(13):6699-713.

224. Yang M, Vesterlund M, Siavelis I, Moura-Castro LH, Castor A, Fioretos T, et al. Proteogenomics and Hi-C Reveal Transcriptional Dysregulation in High Hyperdiploid Childhood Acute Lymphoblastic Leukemia. Nat Commun (2019) 10(1):1519. doi: 10.1038/s41467-019-09469-3

225. Rivas MA, Meydan C, Chin CR, Challman MF, Kim D, Bhinder B, et al. Smc3 Dosage Regulates B Cell Transit Through Germinal Centers and Restricts Their Malignant Transformation. Nat Immunol (2021) 22 (2):240-53. doi: 10.1038/s41590-020-00827-8

226. Lhoumaud P, Badri S, Rodriguez-Hernaez J, Sakellaropoulos T, Sethia G, Kloetgen A, et al. NSD2 Overexpression Drives Clustered Chromatin and Transcriptional Changes in a Subset of Insulated Domains. Nat Commun (2019) 10(1):4843.

227. Yusufova N, Kloetgen A, Teater M, Osunsade A, Camarillo JM, Chin CR, et al. Histone H1 Loss Drives Lymphoma by Disrupting 3D Chromatin Architecture. Nature (2021) 589(7841):299-305.

228. Donaldson-Collier MC, Sungalee S, Zufferey M, Tavernari D, Katanayeva N, Battistello E, et al. EZH2 Oncogenic Mutations Drive Epigenetic, Transcriptional, and Structural Changes Within Chromatin Domains. Nat Genet (2019) 51(3):517-28. doi: 10.1038/s41588-018-0338-y

229. Huang Y, Mouttet B, Warnatz HJ, Risch T, Rietmann F, Frommelt F, et al. The Leukemogenic Tcf3-Hlf Complex Rewires Enhancers Driving Cellular Identity and Self-Renewal Conferring EP300 Vulnerability. Cancer Cell (2019) 36(6):630-44 e9. doi: 10.1016/j.ccell.2019.10.004

230. Mikulasova A, Trevisan-Herraz M, Fung K, Ashby C, Karataraki N, Morgan GJ, et al. Epigenomic Translocation of H3K4me3 Broad Domains Following Super-Enhancer Hijacking. bioRxiv (2020) doi: 2020.02.12.938563

231. Hnisz D, Weintraub AS, Day DS, Valton AL, Bak RO, Li CH, et al. Activation of Proto-Oncogenes by Disruption of Chromosome Neighborhoods. Science (2016) 351(6280):1454-8. doi: 10.1126/science.aad9024

232. Li Y, Liao Z, Luo H, Benyoucef A, Kang Y, Lai Q, et al. Alteration of CTCFAssociated Chromatin Neighborhood Inhibits TAL1-Driven Oncogenic Transcription Program and Leukemogenesis. Nucleic Acids Res (2020) 48 (6):3119-33.

233. Allinne J, Pichugin A, Iarovaia O, Klibi M, Barat A, Zlotek-Zlotkiewicz E, et al. Perinucleolar Relocalization and Nucleolin as Crucial Events in the Transcriptional Activation of Key Genes in Mantle Cell Lymphoma. Blood (2014) 123(13):2044-53.

234. Wu P, Li T, Li R, Jia L, Zhu P, Liu Y, et al. 3D Genome of Multiple Myeloma Reveals Spatial Genome Disorganization Associated with Copy Number Variations. Nat Commun (2017) 8(1):1937.

235. Smith ER, Capo-Chichi CD, Xu XX. Defective Nuclear Lamina in Aneuploidy and Carcinogenesis. Front Oncol (2018) 8:529. doi: 10.3389/fonc.2018.00529
236. Kloetgen A, Thandapani P, Tsirigos A, Aifantis I. 3d Chromosomal Landscapes in Hematopoiesis and Immunity. Trends Immunol (2019) 40 (9):809-24. doi: 10.1016/j.it.2019.07.003

237. Rivas MA, Melnick AM. Role of Chromosomal Architecture in Germinal Center B Cells and Lymphomagenesis. Curr Opin Hematol (2019) 26(4):294302. doi: 10.1097/MOH.0000000000000505

238. Herranz D, Ambesi-Impiombato A, Palomero T, Schnell SA, Belver L, Wendorff AA, et al. A NOTCH1-driven MYC Enhancer Promotes T Cell Development, Transformation and Acute Lymphoblastic Leukemia. Nat Med (2014) 20(10):1130-7. doi: 10.1038/nm.3665

239. Cancer Genome Atlas Research N, Ley TJ, Miller C, Ding L, Raphael BJ, Mungall AJ, et al. Genomic and Epigenomic Landscapes of Adult De Novo Acute Myeloid Leukemia. N Engl J Med (2013) 368(22):2059-74. doi: 10.1056/NEJMoa1301689

240. Thol F, Bollin R, Gehlhaar M, Walter C, Dugas M, Suchanek KJ, et al. Mutations in the Cohesin Complex in Acute Myeloid Leukemia: Clinical and Prognostic Implications. Blood (2014) 123(6):914-20. doi: 10.1182/blood-2013-07-518746

241. Viny AD, Bowman RL, Liu Y, Lavallee VP, Eisman SE, Xiao W, et al. Cohesin Members Stag1 and Stag2 Display Distinct Roles in Chromatin Accessibility and Topological Control of HSC Self-Renewal and Differentiation. Cell Stem Cell (2019) 25(5):682-96 e8. doi: 10.1016/j.stem.2019.08.003

242. Paulsson K, Lilljebjorn H, Biloglav A, Olsson L, Rissler M, Castor A, et al. The Genomic Landscape of High Hyperdiploid Childhood Acute Lymphoblastic Leukemia. Nat Genet (2015) 47(6):672-6. doi: 10.1038/ng.3301

243. Ding L, Ley TJ, Larson DE, Miller CA, Koboldt DC, Welch JS, et al. Clonal Evolution in Relapsed Acute Myeloid Leukaemia Revealed by Whole-Genome Sequencing. Nature (2012) 481(7382):506-10. doi: 10.1038/nature10738

244. Solomon DA, Kim T, Diaz-Martinez LA, Fair J, Elkahloun AG, Harris BT, et al. Mutational Inactivation of STAG2 Causes Aneuploidy in Human Cancer. Science (2011) 333(6045):1039-43. doi: 10.1126/science.1203619

245. Scourzic L, Couronne L, Pedersen MT, Della Valle V, Diop M, Mylonas E, et al DNMT3A(R882H) Mutant and Tet2 Inactivation Cooperate in the Deregulation of DNA Methylation Control to Induce Lymphoid Malignancies in Mice. Leukemia (2016) 30(6):1388-98. doi: 10.1038/leu.2016.29

246. Quivoron C, Couronne L, Della Valle V, Lopez CK, Plo I, Wagner-Ballon O, et al. TET2 Inactivation Results in Pleiotropic Hematopoietic Abnormalities in Mouse and is a Recurrent Event During Human Lymphomagenesis. Cancer Cell (2011) 20(1):25-38. doi: 10.1016/j.ccr.2011.06.003

247. Couronne L, Bastard C, Bernard OA. TET2 and DNMT3A Mutations in Human T-cell Lymphoma. N Engl J Med (2012) 366(1):95-6. doi: 10.1056/NEJMc1111708

248. Liu EM, Martinez-Fundichely A, Diaz BJ, Aronson B, Cuykendall T, MacKay $\mathrm{M}$, et al. Identification of Cancer Drivers at CTCF Insulators in 1,962 Whole Genomes. Cell Syst (2019) 8(5):446-55 e8. doi: 10.1016/j.cels.2019.04.001

249. Klein IA, Resch W, Jankovic M, Oliveira T, Yamane A, Nakahashi H, et al. Translocation-Capture Sequencing Reveals the Extent and Nature of Chromosomal Rearrangements in B Lymphocytes. Cell (2011) 147(1):95106. doi: 10.1016/j.cell.2011.07.048

250. Chiarle R, Zhang Y, Frock RL, Lewis SM, Molinie B, Ho YJ, et al. Genome-Wide Translocation Sequencing Reveals Mechanisms of Chromosome Breaks and Rearrangements in B Cells. Cell (2011) 147(1):107-19. doi: 10.1016/j.cell.2011.07.049

251. Canela A, Maman Y, Jung S, Wong N, Callen E, Day A, et al. Genome Organization Drives Chromosome Fragility. Cell (2017) 170(3):507-21.e18. doi: 10.1016/j.cell.2017.06.034

252. Yang M, Safavi S, Woodward EL, Duployez N, Olsson-Arvidsson L, Ungerback J, et al. 13q12.2 Deletions in Acute Lymphoblastic Leukemia Lead to Upregulation of FLT3 Through Enhancer Hijacking. Blood (2020) 136(8):946-56. doi: 10.1182/blood.2019004684

253. Law PJ, Sud A, Mitchell JS, Henrion M, Orlando G, Lenive O, et al. GenomeWide Association Analysis of Chronic Lymphocytic Leukaemia, Hodgkin Lymphoma and Multiple Myeloma Identifies Pleiotropic Risk Loci. Sci Rep (2017) 7:41071. doi: 10.1038/srep41071

254. Saillard C, Guermouche H, Derrieux C, Bruneau J, Frenzel L, Couronne L, et al. Response to 5-Azacytidine in a Patient With TET2-mutated Angioimmunoblastic T-cell Lymphoma and Chronic Myelomonocytic Leukaemia Preceded by an EBV-positive Large B-cell Lymphoma. Hematol Oncol (2017) 35(4):864-8. doi: 10.1002/hon.2319

255. Italiano A, Soria JC, Toulmonde M, Michot JM, Lucchesi C, Varga A, et al. Tazemetostat, an EZH2 Inhibitor, in Relapsed or Refractory B-cell non- 
Hodgkin Lymphoma and Advanced Solid Tumours: A First-in-Human, Open-Label, Phase 1 Study. Lancet Oncol (2018) 19(5):649-59. doi: 10.1016/ S1470-2045(18)30145-1

256. Li L, Guo F, Gao Y, Ren Y, Yuan P, Yan L, et al. Single-Cell Multi-Omics Sequencing of Human Early Embryos. Nat Cell Biol (2018) 20(7):847-58. doi: 10.1038/s41556-018-0123-2

257. Wei X, Xiang Y, Shan R, Peters DT, Sun T, Lin X, et al. Multi-Omics Analysis of Chromatin Accessibility and Interactions With Transcriptome by Hicar. bioRxiv (2020). doi: 10.1101/2020.11.02.366062

258. Beagrie RA, Scialdone A, Schueler M, Kraemer DC, Chotalia M, Xie SQ, et al. Complex Multi-Enhancer Contacts Captured by Genome Architecture Mapping. Nature (2017) 543(7646):519-24. doi: 10.1038/nature21411

259. Ma S, Zhang B, LaFave LM, Earl AS, Chiang Z, Hu Y, et al. Chromatin Potential Identified by Shared Single-Cell Profiling of RNA and Chromatin. Cell (2020) 183(4):1103-16 e20. doi: 10.1016/j.cell.2020.09.056

260. Jinek M, Chylinski K, Fonfara I, Hauer M, Doudna JA, Charpentier E. A Programmable Dual-RNA-Guided DNA Endonuclease in Adaptive Bacterial Immunity. Science (2012) 337(6096):816-21. doi: 10.1126/science.1225829

261. Quinodoz S, Guttman M. Long Noncoding RNAs: An Emerging Link Between Gene Regulation and Nuclear Organization. Trends Cell Biol (2014) 24(11):651-63. doi: 10.1016/j.tcb.2014.08.009
262. Laffleur B, Lim J, Zhang W, Chen Y, Pefanis E, Bizarro J, et al. Noncoding RNA Processing by DIS3 Regulates Chromosomal Architecture and Somatic Hypermutation in B Cells. Nat Genet (2021) 53(2):230-42. doi: 10.1038/ s41588-020-00772-0

263. Wang Y, Zolotarev N, Yang CY, Rambold A, Mittler G, Grosschedl R. A Prion-like Domain in Transcription Factor EBF1 Promotes Phase Separation and Enables B Cell Programming of Progenitor Chromatin. Immunity (2020) 53(6):1151-67.e6. doi: 10.1016/j.immuni.2020.10.009

264. Alberti S, Dormann D. Liquid-Liquid Phase Separation in Disease. Annu Rev Genet (2019) 53:171-94. doi: 10.1146/annurev-genet-112618-043527

Conflict of Interest: The authors declare that the research was conducted in the absence of any commercial or financial relationships that could be construed as a potential conflict of interest.

Copyright (๑) 2021 Scourzic, Salataj and Apostolou. This is an open-access article distributed under the terms of the Creative Commons Attribution License (CC BY). The use, distribution or reproduction in other forums is permitted, provided the original author(s) and the copyright owner(s) are credited and that the original publication in this journal is cited, in accordance with accepted academic practice. No use, distribution or reproduction is permitted which does not comply with these terms. 